Article

\title{
Sun-Angle Effects on Remote-Sensing Phenology Observed and Modelled Using Himawari-8
}

\author{
Xuanlong Ma ${ }^{1,2, *(\mathbb{D}}$, Alfredo Huete ${ }^{2}$, Ngoc Nguyen Tran ${ }^{2,3}$, Jian Bi ${ }^{1}$, Sicong Gao ${ }^{2} \odot$ and \\ Yelu Zeng 4 (D) \\ 1 College of Earth and Environmental Sciences, Lanzhou University, Lanzhou, Gansu 730000, China; \\ bijian@lzu.edu.cn \\ 2 School of Life Sciences, University of Technology Sydney, Ultimo NSW 2007, Australia; \\ alfredo.huete@uts.edu.au (A.H.); ngoc.tran@uts.edu.au (N.N.T.); sicong.gao@student.uts.edu.au (S.G.) \\ 3 School of Information and Communication Technology, Hanoi University of Science and Technology, \\ Hanoi 10000, Vietnam \\ 4 Department of Global Ecology, Carnegie Institution for Science, Stanford, CA 94305, USA; \\ yzeng@carnegiescience.edu \\ * Correspondence: xlma@lzu.edu.cn
}

Received: 31 March 2020; Accepted: 21 April 2020; Published: 23 April 2020

\begin{abstract}
Satellite remote sensing of vegetation at regional to global scales is undertaken at considerable variations in solar zenith angle (SZA) across space and time, yet the extent to which these SZA variations matter for the retrieval of phenology remains largely unknown. Here we examined the effect of seasonal and spatial variations in SZA on retrieving vegetation phenology from time series of the Normalized Difference Vegetation Index (NDVI) and Enhanced Vegetation Index (EVI) across a study area in southeastern Australia encompassing forest, woodland, and grassland sites. The vegetation indices (VI) data span two years and are from the Advanced Himawari Imager (AHI), which is onboard the Japanese Himawari-8 geostationary satellite. The semi-empirical RossThick-LiSparse-Reciprocal (RTLSR) bidirectional reflectance distribution function (BRDF) model was inverted for each spectral band on a daily basis using 10-minute reflectances acquired by H-8 AHI at different sun-view geometries for each site. The inverted RTLSR model was then used to forward calculate surface reflectance at three constant SZAs $\left(20^{\circ}, 40^{\circ}, 60^{\circ}\right)$ and one seasonally varying SZA (local solar noon), all normalised to nadir view. Time series of NDVI and EVI adjusted to different SZAs at nadir view were then computed, from which phenological metrics such as start and end of growing season were retrieved. Results showed that NDVI sensitivity to SZA was on average nearly five times greater than EVI sensitivity. VI sensitivity to SZA also varied among sites (biome types) and phenological stages, with NDVI sensitivity being higher during the minimum greenness period than during the peak greenness period. Seasonal SZA variations altered the temporal profiles of both NDVI and EVI, with more pronounced differences in magnitude among NDVI time series normalised to different SZAs. When using VI time series that allowed SZA to vary at local solar noon, the uncertainties in estimating start, peak, end, and length of growing season introduced by local solar noon varying SZA VI time series, were 7.5, 3.7, 6.5, and 11.3 days for NDVI, and 10.4, $11.9,6.5$, and 8.4 days for EVI respectively, compared to VI time series normalised to a constant SZA. Furthermore, the stronger SZA dependency of NDVI compared with EVI, resulted in up to two times higher uncertainty in estimating annual integrated VI, a commonly used remote-sensing proxy for vegetation productivity. Since commonly used satellite products are not generally normalised to a constant sun-angle across space and time, future studies to assess the sun-angle effects on satellite applications in agriculture, ecology, environment, and carbon science are urgently needed. Measurements taken by new-generation geostationary (GEO) satellites offer an important opportunity to refine this assessment at finer temporal scales. In addition, studies are needed to evaluate the suitability of different BRDF models for normalising sun-angle across a broad spectrum of vegetation
\end{abstract}


structure, phenological stages and geographic locations. Only through continuous investigations on how sun-angle variations affect spatiotemporal vegetation dynamics and what is the best strategy to deal with it, can we achieve a more quantitative remote sensing of true signals of vegetation change across the entire globe and through time.

Keywords: geostationary land application; BRDF; vegetation index; phenology; vegetation productivity

\section{Introduction}

Resolving accurate vegetation dynamics not confounded by varying atmosphere condition, soil background, and sun-view geometry have been a long-running and prominent pursuit of the remote-sensing community [1-8]. Satellite applications at regional to global scale involve considerate variations in sun-angle across space and time [9-11], yet to date the spatiotemporal sun-angle variations have not been explicitly considered in the majority of satellite vegetation applications. For instance, the widely used MODerate Resolution Imaging Spectroradiometer (MODIS) surface reflectance (MOD09) [12], vegetation indices product (MOD13) [13] do not correct both view and illumination geometry, and the MCD43 nadir bidirectional reflectance distribution function (BRDF) adjusted reflectance (NBAR) product normalised to nadir view angle, still allows for sun-angle to vary at local solar noon across time [14].

Sun-angle variation can alter surface reflectance and vegetation indices (VIs) [15-21], especially for three-dimensionally complex vegetated surfaces such as forest and woodland [22]. In the meantime, for any given location observational sun-angle of commonly used spaceborne sensors such as Landsat, MODIS, and Advanced Very High Resolution Radiometer (AVHRR) can vary considerably across time $[9,10]$. Likewise, for any given time sun-angle can also vary across space as a function of latitude. For instance, the solar zenith angle (SZA), the angle between the zenith and the center of the Sun's disc, can vary from around $70^{\circ}$ in winter to around $30^{\circ}$ in summer over mid-latitude in Northern Hemisphere $\left(40^{\circ} \mathrm{N}\right)$ for Landsat acquisition [10]. A similar degree of variation in SZA across time also applies to the National Aeronautics and Space Administration's (NASA) Earth Observation System (EOS)-Terra acquisition [9], National Oceanic and Atmospheric Administration (NOAA)'s AVHRR [23], the new Suomi National Polar-Orbiting Partnership (Suomi-NPP)-Visible Infrared Imaging Radiometer Suite (VIIRS) [24], together with all other sensors onboard low-Earth-orbiting (LEO) satellites. However, to date we still do not know much about the extent of the uncertainty caused by sun-angle variation on surface reflectance and VIs and how this will be propagated to the retrieval of vegetation parameters, nor do we know if an optimal sun-angle correction approach, and also a universal "best" sun-angle exists, across a broad spectrum of vegetation structural classes and latitudes. These knowledge gaps need to be confronted and filled by the remote-sensing community in order for the users in various sectors to more confidently use satellite measurements in their vegetation applications.

Retrieving vegetation phenology from time series of satellite measured vegetation indices is a scientific application that is particularly sensitive to spatiotemporal sun-angle variations. This is because seasonal variations in "true" vegetation signals are confounded by seasonal variations in sun-angle, e.g., vegetation in a temperate forest is greenest during the summer when the SZA is small and is lowest during the winter when the SZA is large [5]. As such, seasonal sun-angle variations can bring in uncertainties to the retrieval of phenological metrics [5,25-28]. Using MODIS observations, Bhandari et al. reported that seasonal viewing and illumination geometry effects can produce notable variations in the Normalized Difference Vegetation Index (NDVI) amplitude value and phase shift in both NDVI and the Enhanced Vegetation Index (EVI) over Australian woodland and open forest sites [25]. Similarly, Ma et al. found that seasonal sun-angle variation alone can cause more than 2 weeks of uncertainty in estimating phenological transitional dates using MODIS NDVI over tropical 
savannas [28]. Recently, scientific discussions on dry season Amazon rainforest greenup further stressed the importance of considering sun-angle effect as satellite data has been a pillar of global change research [11,29-32].

Despite the progress made so far, commonly used data for assessing sun-angle effects are taken by LEO satellites, which can only revisit a location 1-2 times per day (e.g., EOS-Terra/Aqua-MODIS, NOAA-AVHRR) or every 16 days (e.g., Landsat). The use of LEO data for assessing sun-angle effects is associated with an important constraint due to limited angular sampling within each day by the LEO satellites. Therefore, assumptions of stable surface anisotropy over a certain period (e.g., 16 days) have to be made to be able to have enough cloud-free observations for BRDF model inversion and sun-view geometry normalisation [14]. This limitation imposes three constraints on using LEO data for assessing sun-angle effects. First, within such a short period there is only a rather restricted variation in sun-angle for any given location which means extrapolation has to be made beyond the observational range. Second, cloud coverage may further reduce the number of clear observations within such a short period, causing a less reliable model inversion due to a smaller degree of freedom. Lastly, even if enough cloud-free observations can be acquired, over regions such as global drylands where rapid surface change can occur with rainfall-induced vegetation growth, the assumption of stable anisotropy within an 8-day time window may not necessarily be adequately satisfied. The limitation of using LEO for assessing and normalising the sun-angle effect may be relieved by using the measurements taken by geostationary (GEO) satellites, which provide sub-daily reflectance acquired at a large range of sun-angle conditions from sunrise to sunset, from which a BRDF model can be inverted on a daily basis [33].

With the development in sensor technologies and increasing computational power available to users, GEO satellites, which have been traditionally used for the atmosphere and ocean science, are now gaining attention in land applications [34-45]. Over the past few years a new generation of GEO satellites have been launched, including Himawari-8 (Japan), FengYun (FY)-4A (China), and Geostationary Operational Environmental Satellite (GOES)-16 (USA), all with high radiometric and temporal resolutions. For instance, the Japanese Himawari-8 (H-8) geostationary satellite, launched in 2014, carries an Advanced Himawari Imager (AHI) that have spectral bands similar to MODIS [46]. H-8 AHI scans the full disk at 10-minutes intervals and generate 144 images each day, covering the entire sun-angle variations from sunrise to sunset. The data from $\mathrm{H}-8 \mathrm{AHI}$, therefore, offer unprecedented opportunities to assess sun-angle effect on remote sensing of vegetation dynamics at finer temporal scales.

The overarching aim of this study was to gain a better understanding of sun-angle influences on time series of vegetation indices and the retrieved phenological metrics using H-8 AHI measurements. Specifically, the objectives are to quantify the sensitivity of commonly used vegetation indices to sun-angle variations in different biome types and phenological stages and further assess the seasonal sun-angle effect on the temporal profiles of VIs and retrieved phenological metrics.

\section{Data and Method}

\subsection{Study Area}

We focused on a sub-region in southeastern Australia (SE Australia) $\left(145.5^{\circ} \mathrm{E}-152^{\circ} \mathrm{E}, 33^{\circ} \mathrm{S}-36^{\circ} \mathrm{S}\right.$, Figure 1). There is a strong rainfall gradient with mean annual precipitation (MAP) declines from more than $1500 \mathrm{~mm}$ over the eastern coastal region to less than $400 \mathrm{~mm}$ over the western dryland agricultural region (Figure 1). There is a corresponding transition of vegetation from forest and woodland in the east, to pastures and cropland in the west, mostly rainfed (Figure 1). 


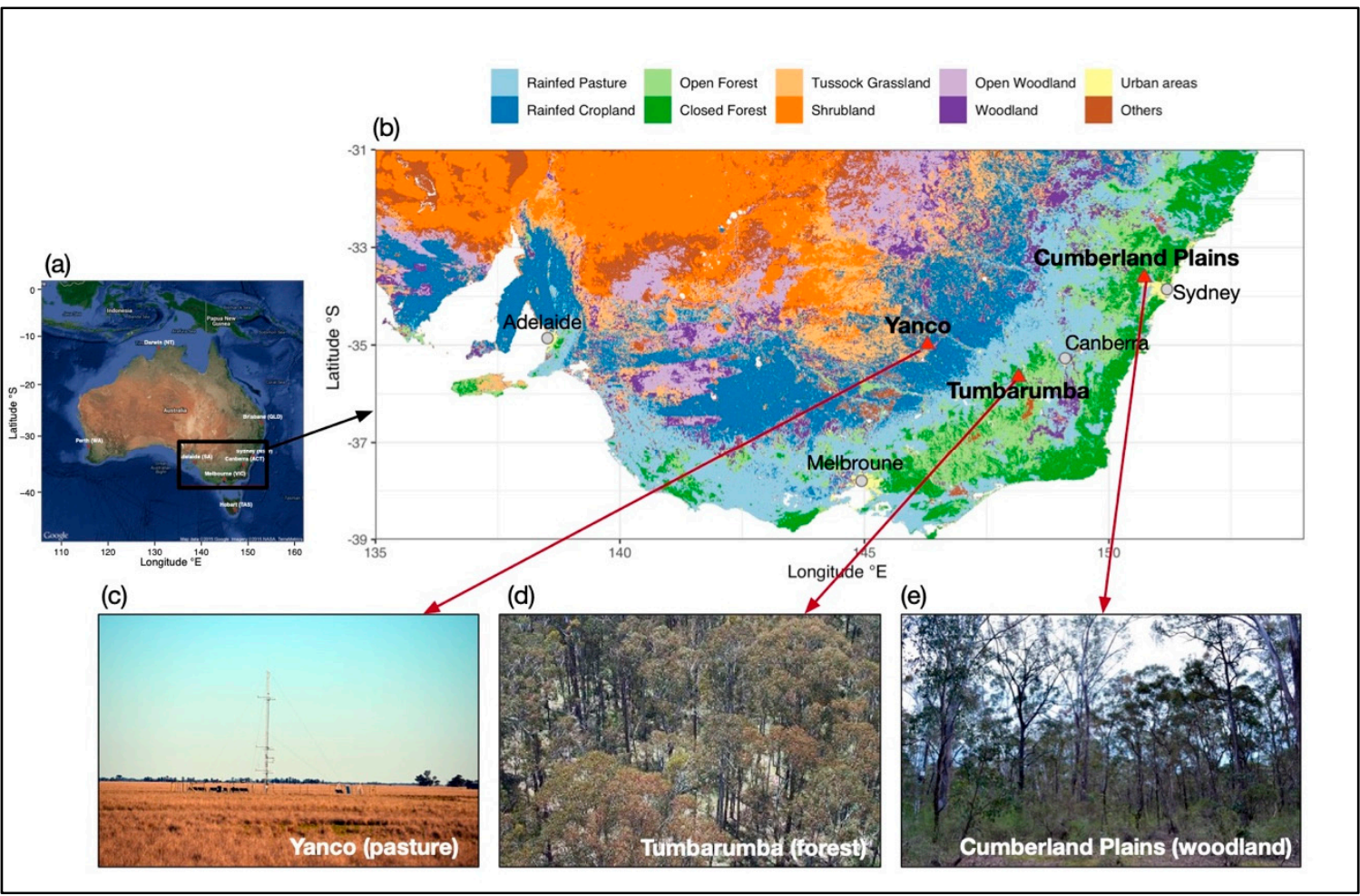

Figure 1. Spatial extent of the Southeastern Australia (SE Australia) study area. The panel (a) shows the spatial extent of the SE Australia study area over the Australian continent (image source: Google Earth). The red triangles on panel (b) indicate the locations of the three local sites. Background of panel (b) is the map of Australian Dynamic Land Cover Map (v2.1), provided by Geosciences Australia. Panels c-e are the photographs showing ground-view of each local site (image credit: TERN, https://www.ozflux.com).

Within the SE Australia study area, three well-characterised local sites were selected, representing different biome types and rainfall regimes: Tumbarumba (Eucalyptus forest, mean annual precipitation, MAP $=1924 \mathrm{~mm}$ ), Cumberland Plains (Eucalyptus woodland, MAP = $806 \mathrm{~mm}$ ), and Yanco (pasture, MAP $=472 \mathrm{~mm})($ Figure 1 and Table 1$)$. The spatial extent of each site was $3 \mathrm{~km} \times 3 \mathrm{~km}$ corresponding to the $3 \times 3$ pixels window to extract $\mathrm{H}-8$ AHI time series for each site. These sites were used to investigate the sun-angle influence on vegetation indices and phenology at the site level.

Table 1. Summary of vegetation types and climatology of the three local sites, MAP is mean annual precipitation; MAT is mean annual temperature.

\begin{tabular}{|c|c|c|c|c|c|c|}
\hline Site & Longitude $\left({ }^{\circ} \mathrm{E}\right)$ & Latitude $\left({ }^{\circ} \mathrm{S}\right)$ & Elevation (m) & Vegetation Type & $\begin{array}{c}\text { MAP }^{*} \\
\left(\mathrm{~mm} \mathrm{yr}^{-1}\right)\end{array}$ & MAT $*\left({ }^{\circ} \mathrm{C}\right)$ \\
\hline Tumbarumba & 148.1517 & 35.6566 & 1249 & Eucalyptus forest & 1924.2 & 9.6 \\
\hline Cumberland Plains & 150.7236 & 33.6153 & 54 & $\begin{array}{l}\text { Eucalyptus } \\
\text { woodlands }\end{array}$ & 806.3 & 18.1 \\
\hline Yanco & 146.2907 & 34.9893 & 128 & Pasture & 472.1 & 17.3 \\
\hline
\end{tabular}

${ }^{*}$ cited from [47].

\subsection{Himawari-8 Advanced Himawari Imager Data}

Himawari-8 is a Japanese geostationary satellite launched on 7 October 2014 and is positioned above $140.7^{\circ} \mathrm{E}$ and $0.02^{\circ} \mathrm{S}$ [47]. The AHI on board the H-8 satellite scans the Asia-Pacific region every 10 minutes at spatial resolution $500 \mathrm{~m}$ for the Red band (channel 3, $640 \mathrm{~nm}$ ) and $1000 \mathrm{~m}$ for the Blue (channel 1, $470 \mathrm{~nm}$ ) and near infrared (NIR, channel 4, $860 \mathrm{~nm}$ ) bands, respectively. The data from Red band were averaged over $2 \times 2$ pixels to match the resolution of the other bands. Nearly two years of 
10-minutes H-8 AHI surface reflectance data were processed from March 2016 to December 2017 by the Australian Bureau of Meteorology (BoM) using the multi-angle implementation of atmospheric correction (MAIAC) algorithm [48]. The MAIAC was originally developed for MODIS to retrieve aerosol and perform atmospheric correction over the land surface [49] and has shown to be suitable for the processing of H-8 AHI data as well [42]. It should be noted that the MAIAC code we used in this study for the H-8 AHI data is still under development in order to optimise its performance, although we do not expect that future code adjustment should have significant impacts on the results of this study. For the selected local sites, 10 -minute measurements within a $3 \times 3$ pixels window $\left(9 \mathrm{~km}^{2}\right)$ of $\mathrm{H}-8$ AHI data were extracted across the two years of study period. As the three study sites were chosen with the consideration of homogeneity in vegetation cover types, the $3 \mathrm{~km} \times 3 \mathrm{~km}$ window should sufficiently account for the geolocation error of H-8 AHI, which was reported to be $150 \mathrm{~m}$ (north-south) $\times 500 \mathrm{~m}$ (east-west) [50]. Figure 2 shows a workflow diagram indicating major steps involved in $\mathrm{H}-8$ data preprocessing, BRDF modelling (Sec. 2.3), and phenology retrieval (Sec. 2.5).

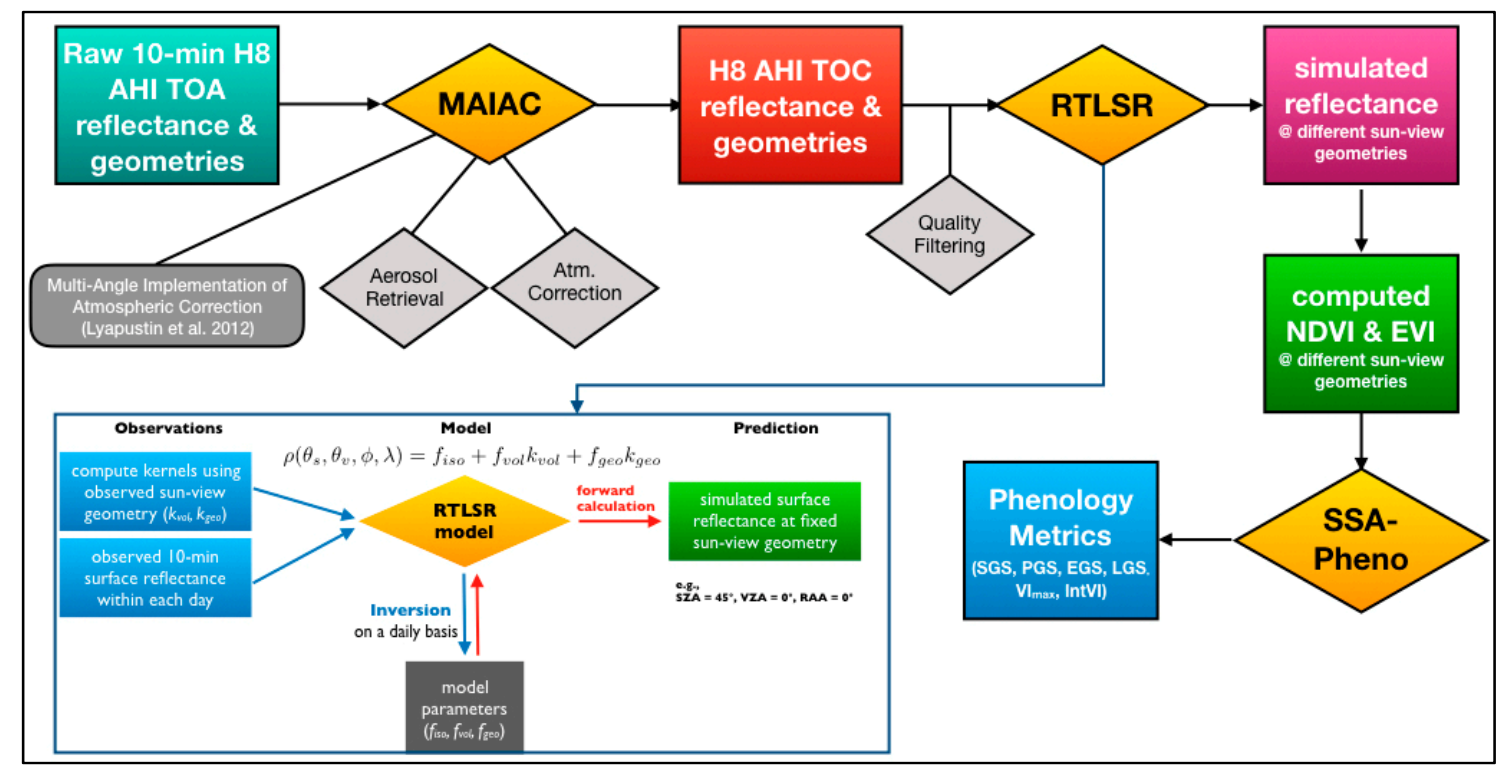

Figure 2. Workflow diagram of Japanese Himawari-8 (H-8) Advanced Himawari Imager (AHI) data preprocessing, bidirectional reflectance distribution function (BRDF) modelling, and phenological metrics retrieval.

Figure 3 shows an example H-8 AHI sun-view geometry at one of the three local sites. H-8 AHI observes the same target always from a fixed angle, resulting in fixed view zenith angle and view azimuth angles for each pixel. For the three sites we selected, the view zenith angles (VZAs) are $42.28^{\circ}$ for Tumbarumba, $40.72^{\circ}$ for Cumberland Plains, and $41.13^{\circ}$ for Yanco. In contrast to the fixed view angles, the solar zenith angle (SZA) and solar azimuth angle (SAA) of each individual H-8 observation can vary diurnally from sunrise to sunset (Figure 3B,C).

\subsection{Bidirectional Reflectance Distribution Function (BRDF) Modelling}

The surface reflectance can be described using a bidirectional reflectance distribution function (BRDF), which is a function of solar zenith angle, view zenith angle, and both solar azimuth angle and view azimuth angle, with respect to a reference direction [51]. BRDF can be used to standardise surface reflectance taken from varying sun-view geometries to a common geometry to facilitate quantitative comparisons [52]. BRDF is determined by land surface structure and optical properties such as shadow-casting, soil condition, mutual view shadowing, and the spatial distribution of vegetation elements [53]. 


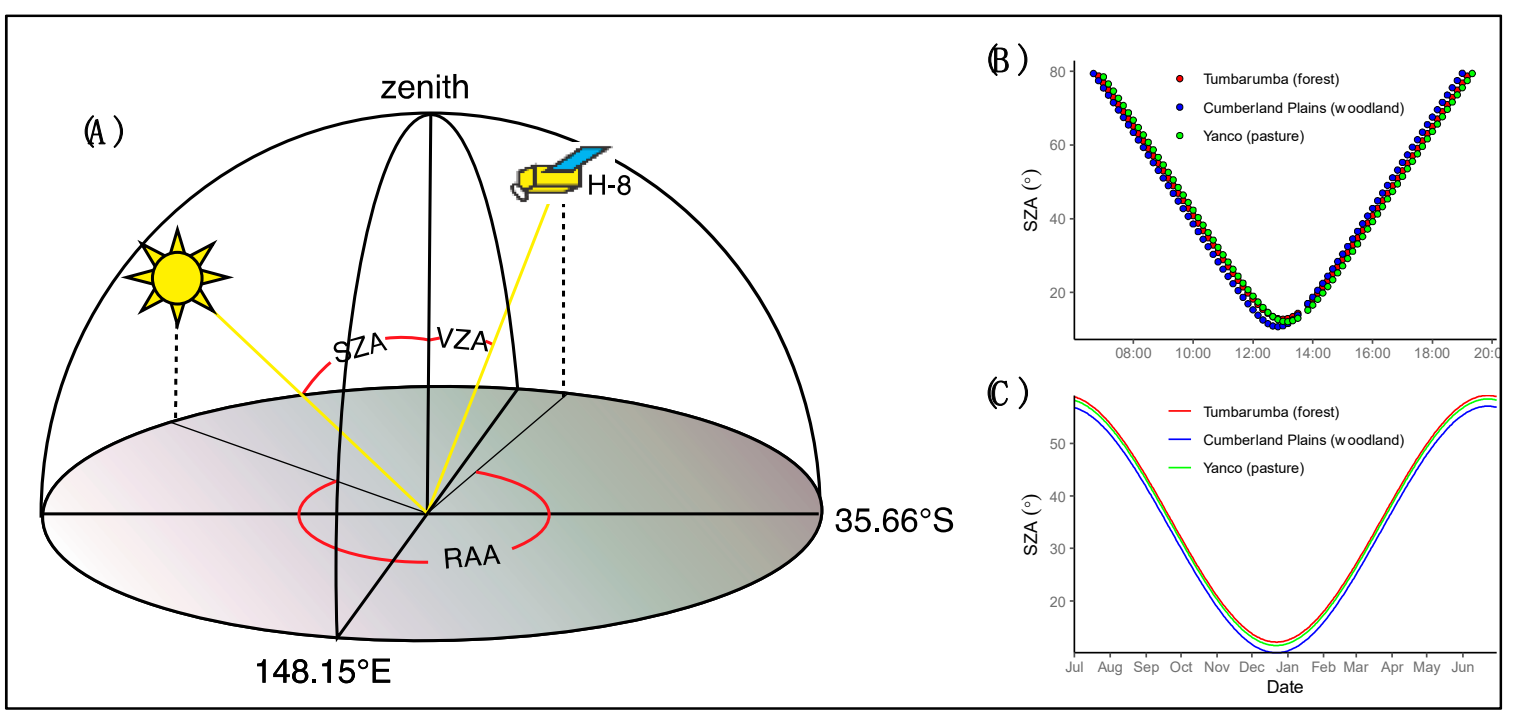

Figure 3. (A) Diagram of an example H-8 AHI sun-view geometry at Tumbarumba site; (B) Diurnal variation in solar zenith angle (SZA) of 10-min H8 AHI observations on 10th of December 2017 at three local sites; (C) seasonal variation in solar noon SZA at three local sites from 1st of July to 30th of June.

In this study, the semi-empirical RossThick-LiSparse Reciprocal (RTLSR) BRDF model $[53,54]$ was used to normalise H-8 AHI surface reflectance to nadir view and different solar zenith angles. The RTLSR model has been used as the standard model for the MCD43 BRDF/NBAR/Albedo product [55]. The utility of the RTLSR model for normalising surface reflectance anisotropy of $\mathrm{H}-8$ geostationary data has also been tested [42,56]. The RTLSR model takes the form given by [57],

$$
R\left(\theta_{s}, \theta_{v}, \phi_{s}, \phi_{v}, \Lambda\right)=f_{\text {iso }}+f_{v o l}(\Lambda) K_{v o l}\left(\theta_{s}, \theta_{v}, \phi_{s}, \phi_{v}\right)+f_{g e o}(\Lambda) K_{g e o}\left(\theta_{s}, \theta_{v}, \phi_{s}, \phi_{v}\right)
$$

where $R\left(\theta_{\mathrm{s}}, \theta_{\mathrm{v}}, \phi_{\mathrm{s}}, \phi_{\mathrm{s}}, \Lambda\right)$ is the BRDF in waveband $\Lambda ; \theta_{\mathrm{s}}$ is solar zenith angle (SZA); $\theta_{\mathrm{v}}$ is VZA; $\phi_{\mathrm{s}}$ is solar azimuth angle (SAA); $\phi_{\mathrm{v}}$ is view azimuth angle (VAA); $\Lambda$ is waveband of width $\Delta \lambda ; f_{\text {iso }}(\Lambda)$ is isotropic parameter of BRDF at waveband $\Lambda ; K_{\mathrm{vol}}$ is the RossThick volume scattering kernel; $K_{\mathrm{geo}}$ is the Li-Sparse-Reciprocal geometric scattering kernel. Full mathematical expressions of $K_{\mathrm{vol}}$ and $K_{\text {geo }}$ can be found in $[53,57,58]$.

The inset of Figure 2 shows the major steps taken for running the RTLSR model first in "inversion-mode" and subsequently in "forward mode". The inversion mode takes the 10-min $\mathrm{H}-8$ surface reflectance and observational Sun-view geometry for any given pixel to invert the three model parameters, $f_{\mathrm{iso}}, f_{\mathrm{vol}}$, and $f_{\mathrm{geo}}$, on a daily basis using multiple linear regression. The BRDF of Equation (1) was assumed to be the same as the measured reflectance from the H-8 AHI sensor. We imposed a lower limit for the model parameters so that all inversions that resulted in negative model parameters $\left(f_{\text {iso }}, f_{\mathrm{vol}}\right.$, and $\left.f_{\text {geo }}\right)$ were excluded from the analysis. We did not impose an upper limit on the three parameters but, instead, assessed the goodness of fit for model inversion to ensure that the observations can be predicted using the fitted model parameters within a predefined error threshold. In addition, the sufficient amount of input observations from H-8 AHI to fit the model allowed a high degree of freedom during the multiple linear regression and the three free parameters, therefore, can be inverted successfully on a daily basis. Before running the inversion, quality flags of H-8 AHI data were used to preserve only good quality observations as the model input. Observations taken when SZA is greater than $70^{\circ}$ (very low sun), which usually occurred in early morning or late afternoon, were also abandoned as larger SZA means a longer path of sunlight travelling through the atmosphere and causes the atmospheric correction model to be less effective.

The goodness of fit for model inversion was evaluated by the coefficient of determination adjusted for the degree of freedom (adjusted $R^{2}$ ), while the accuracy of the model inversion was assessed by the 
root-mean-square error (RMSE) associated with inversion. Low $R^{2}$ and high RMSE signal low model performance and hence low reliability in using the model parameters to adjust reflectance values to the targeting sun-view geometry. Only inversions that resulted in RMSEs lower than a pre-defined threshold value were used later in the "forward-mode". For the three local sites, RMSE for the Red band ranges from 0 to 0.11 (mean $=0.006 \pm 0.007$ ), from 0 to 0.038 (mean $=0.004 \pm 0.003$ ) for the Blue band, and from 0 to 0.09 (mean $=0.017 \pm 0.015$ ) for NIR band. Given the fact that different spectral bands have much different ranges of reflectance values and RMSEs, we used a relative threshold for each band based on normalised RMSE (nRMSE), computed as RMSE normalised by mean reflectance of each band, with nRMSE lower than $20 \%$ considered as acceptable quality inversion. Preliminary analysis showed that after excluding the inversions with nRMSE greater than 20\%, the mean nRMSEs across three local sites and across two years were $6.7 \pm 5.0 \%, 8.1 \pm 5.4 \%$, and $4.9 \pm 4.5 \%$, for Red, Blue, and NIR bands respectively.

Once the three RTLSR model parameters were reliably inverted for each day, the model was then operated in the "forward mode" to calculate daily reflectance at the desired Sun-view geometry (Figure 3). Since the focus of this study is to assess the effect of sun-angle variations on vegetation indices and phenology retrievals, VZA was, therefore, normalised to zero (i.e., nadir view) and SZA was normalised to different scenarios. Four SZA scenarios were used, including three constant SZAs: $20^{\circ}, 40^{\circ}, 60^{\circ}$, which means that SZA is constant across time for any given site, as well as constant across sites; one seasonally varying SZA: local solar noon (LSN), which means that SZA is set as the value as acquired at local solar noon of each day for each site, and hence it varies across time for any given site and is also different across latitude for any given time (Figure 3C). The LSN scenario is equivalent to the MODIS MCD43A4 NBAR-Nadir BRDF adjusted reflectance product [59], which also fixes VZA to nadir but allows SZA to vary across time at local solar noon. The RTLSR model inversion and forward calculation were carried out for Red, Blue, and NIR reflectances, from which NDVI and EVI at different SZA configurations can be computed: $\mathrm{VI}_{\mathrm{S}-20}\left(\mathrm{SZA}=20^{\circ}, \mathrm{VZA}=0^{\circ}, \mathrm{RAA}=0^{\circ}\right), \mathrm{VI}_{\mathrm{S}-40}\left(\mathrm{SZA}=40^{\circ}\right.$, $\left.\mathrm{VZA}=0^{\circ}, \mathrm{RAA}=0^{\circ}\right), \mathrm{VI}_{\mathrm{S}-60}\left(\mathrm{SZA}=60^{\circ}, \mathrm{VZA}=0^{\circ}, \mathrm{RAA}=0^{\circ}\right)$, and $\mathrm{VI}_{\mathrm{S}-\mathrm{LSN}}\left(\mathrm{SZA}=\mathrm{LSN}, \mathrm{VZA}=0^{\circ}\right.$, $\left.\operatorname{RAA}=0^{\circ}\right)$.

\subsection{Vegetation Indices}

Phenology retrieval from satellite remote sensing commonly uses time series of vegetation indices (VIs) [60-64]. VIs are remote-sensing proxies of canopy "greenness", integrating canopy properties such as canopy structure, green leaf area, and canopy leaf chlorophyll content $[65,66]$. The two most widely used VIs for phenology retrievals are the NDVI and EVI. The EVI was proposed as an optimised version of NDVI that effectively reduces influences from varying soil background reflectance and atmospheric conditions [13]. The equations defining NDVI [67] and EVI are:

$$
\begin{gathered}
\text { NDVI }=\frac{\rho_{\text {nir }}-\rho_{\text {red }}}{\rho_{\text {nir }}+\rho_{\text {red }}} \\
\mathrm{EVI}=2.5 \frac{\rho_{\text {nir }}-\rho_{\text {red }}}{\rho_{\text {nir }}+6 \rho_{\text {red }}-7.5 \rho_{\text {blue }}+1}
\end{gathered}
$$

where $\rho_{\text {nir }}, \rho_{\text {red }}$ and $\rho_{\text {blue }}$ are reflectances of the near infrared, red, and blue bands, corresponding to channel $4(860 \mathrm{~nm})$, channel $3(640 \mathrm{~nm})$, and channel $1(470 \mathrm{~nm})$ of the H-8 AHI sensor, respectively [46].

\subsection{Phenology Metrics Retrieval Method}

The SSA-Pheno (singular spectrum analysis for phenology) algorithm, graphically depicted by Figure 4, was used to retrieve the phenological metrics from VI time series [68,69]. Six phenological metrics, including the start of growing season (SGS), peak of growing season (PGS), end of growing season (EGS), length of growing season (LGS), seasonal maximum VI ( $\mathrm{VI}_{\max }$ ) and annual integrated VI (IntVI), were retrieved from the time series of H-8 AHI NDVI and EVI time series. Phenological metrics 
retrieved from time series of VIs normalised to different SZAs will be indicated using the subscripts, e.g., $\mathrm{SGS}_{\mathrm{S}-40}$ and IntNDVI $\mathrm{S}_{-20}$ means the SGS and IntNDVI retrieved from time series of $\mathrm{NDVI}_{\mathrm{S}-40}$.
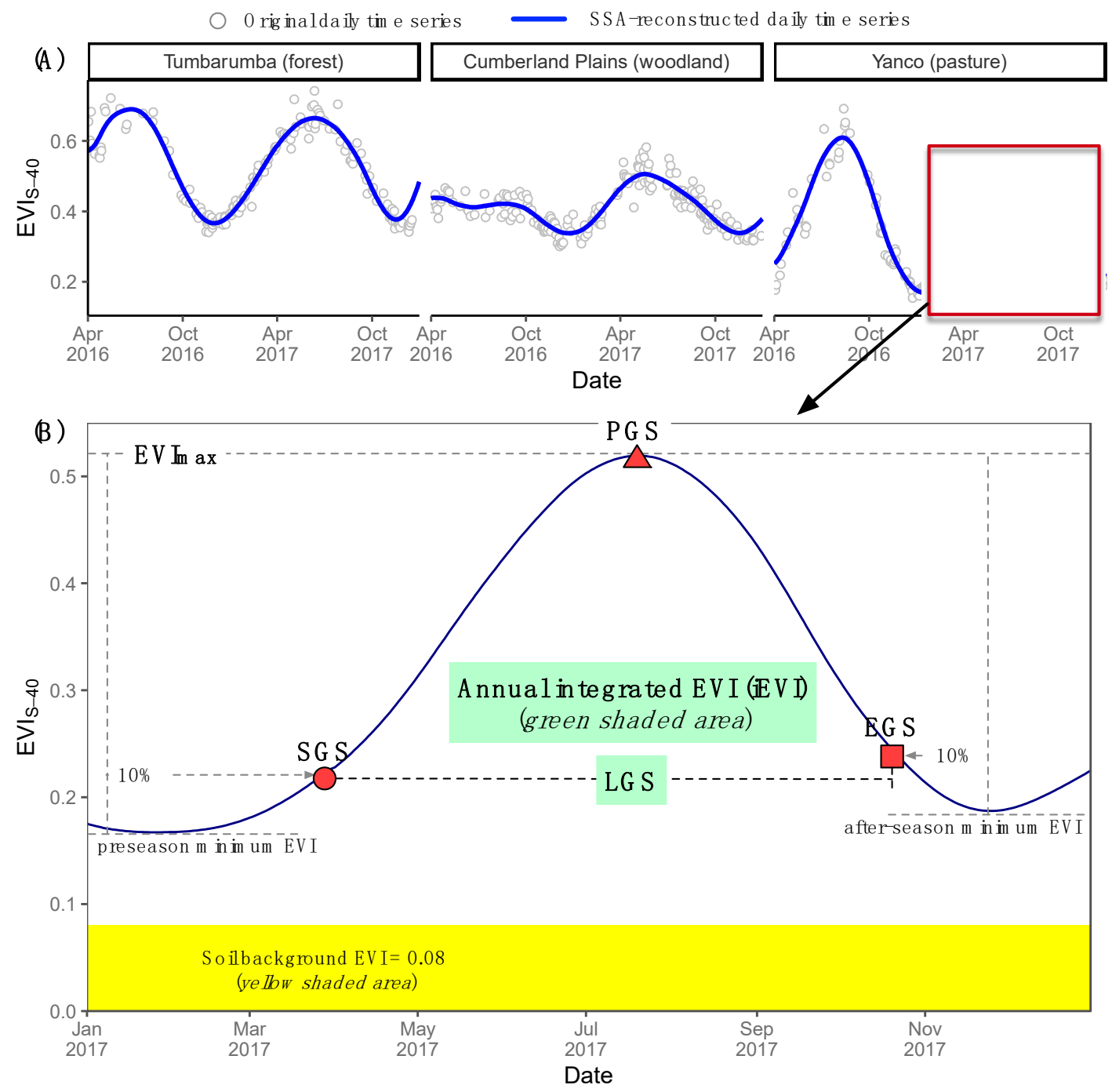

Figure 4. Graphical diagram of the SSA-Pheno (singular spectrum analysis for phenology) algorithm for extracting phenological metrics from VI time series. The top panel (A)shows the H-8 AHI daily Enhanced Vegetation Index (EVI $\mathrm{E}_{\mathrm{S}-40}$ ) time series (grey circles) and SSA-reconstructed (smoothed) EVI $_{\text {S-40 }}$ time series (blue lines) for the three local sites from March 2016 to Dec 2017. The bottom panel (B) shows the diagram of phenology retrieval from the SSA-reconstructed EVI time series of Tumbarumba in 2016-2017 year. Six phenological metrics, including start of growing season (SGS), peak of growing season (PGS), end of growing season (EGS), length of growing season (LGS), seasonal maximum VI $\left(\mathrm{VI}_{\max }\right)$, and annual integrated VI (IntVI), are labelled on the diagram.

The SSA-Pheno algorithm has been tested over Australia across a wide-range of vegetation types and has been demonstrated to be a robust and reliable method for extracting phenological metrics from noisy VI time series $[68,69]$. The SSA (Singular Spectrum Analysis) is a data-adaptive method that has been found to be well-suited to the analysis of nonlinear dynamics in geophysical datasets [70-72]. SSA-Pheno detects SGS when VI reached the value equal to the pre-season minimum VI value (or baseline) plus $10 \%$ of the seasonal VI amplitude (seasonal maximum minus pre-season minimum). Similarly, EGS is detected when VI reaches the values equal to the minimum value after the growing season plus $10 \%$ of seasonal amplitude during the browndown phase (Figure 4). The difference between EGS and SGS is the LGS and the timing when VI reaches its seasonal maximum is PGS. VImax 
is the seasonal maximum VI and IntVI is the annual integrated VI (with soil background VI subtracted), both have been used as a remote sensing proxy for vegetation productivity $[69,73,74]$. Soil background VI was empirically assigned as 0.15 for NDVI and 0.08 for EVI, respectively.

\subsection{Land-Cover Map}

We used the Dynamic Land Cover Dataset (DLCD) from Geoscience Australia and Bureau of Agricultural and Resources Economics and Sciences (https://ecat.ga.gov.au/geonetwork/srv/eng/catalog. search\#/metadata/83868) [75]. The raw DLCD data is in $250 \mathrm{~m}$ spatial resolution, which was resampled to $1 \mathrm{~km}$ to analyze with the comparative H-8 AHI data.

\subsection{Statistics}

The RMSE was calculated to assess the sun-angle variation caused differences in phenological metrics retrieved from time series of VIs normalised to different SZA scenarios,

$$
R M S E=\sqrt{\frac{\sum_{t=1}^{n}\left(x_{0}-x\right)^{2}}{n}}
$$

where $\mathrm{x}_{0}$ is the phenological metrics for any given site from time series of $\mathrm{VI}_{\mathrm{S}-\mathrm{LSN}}$, and $\mathrm{x}$ is the phenological metrics for any given site from time series of $\mathrm{VI}_{\mathrm{S}-40}$, and the $\mathrm{n}$ is the number of samples. To assess the uncertainty relative to sample mean, a normalized RMSE (nRMSE, \%), defined as the ratio between RMSE and the sample mean, was also computed.

The open source R programming language (version 3.6.2) was used for data processing, statistical analysis, and data visualisation [76], with $\mathrm{R}$ packages contributed by the user community (http: //cran.r-project.org).

\section{Results}

3.1. Seasonal Profiles of Normalized Difference Vegetation Index (NDVI) and Enhanced Vegetation Index (EVI) Normalised to Different Solar Zenith Angles (SZAs)

Figure 5 shows the time series of NDVI and EVI normalised to different SZAs. Smaller SZA resulted in lower NDVI, with the magnitude of NDVI S-LSN was close to that of NDVI $_{S-20}$ due to the selection of the lowest SZA within each day to generate the $\mathrm{NDVI}_{\mathrm{S}-\mathrm{LSN}}$ (Figure 5). In comparison, sun-angle had a much smaller effect on the profiles of EVI (Figure 5). Greater SZA resulted in higher EVI over the minimum greenness period (the period when EVI declines from highest to the lowest within a growing season), but this effect was reversed in the peak greenness period (the period when EVI increases form the lowest to the highest within a growing season) (Figure 5).

\subsection{Sensitivity of NDVI and EVI to Sun-Angle Variations}

Figure 6 presents the cross-site comparison of the variations of NDVI and EVI in relation to SZAs over two phenological stages, the peak greenness period and the minimum greenness period. Sensitivity of VI to change in SZA (i.e., change in VI per degree SZA change) was also computed. Since NDVI and EVI can have different sensitivities merely because they have different dynamic range (NDVI tends to have higher value than EVI), and different sites and phenological stages can also have different VI sensitivity to SZA simply because of the difference in the amount of green foliage. Therefore, to facilitate the comparisons of VI sensitivity to SZA variations between VIs, among sites and between phenological stages, normalised VIs were computed by dividing all VIs by their corresponding $\mathrm{VI}_{\mathrm{S}-20}$ at any given site/date. NDVI increased with the increase of SZA, with the lowest NDVI found when the SZA is the smallest (Figure 6A). By contrast, EVI did not show a single response to SZA variations between phenological stages, with negative response to the increase in SZA during the peak greenness period and positive response during the minimum greenness period (Figure 6B). 

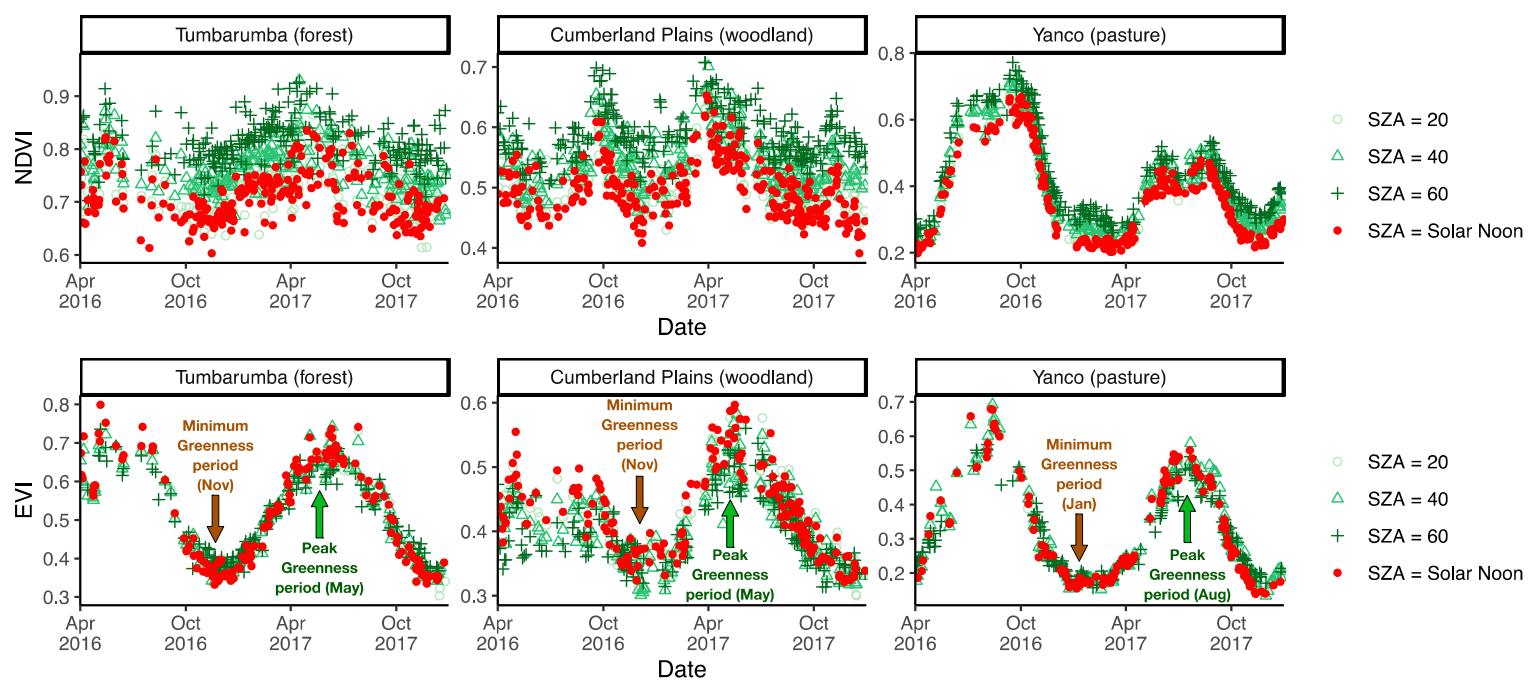

Figure 5. Seasonal profiles of BRDF-corrected Normalized Difference Vegetation Index (NDVI) and Enhanced Vegetation Index (EVI) with different SZAs from 2016 to 2017 for the three local sites. All NDVIs have been adjusted to the nadir view, with three seasonally constant SZA cases: SZA $=20^{\circ}$, $\mathrm{SZA}=40^{\circ}, \mathrm{SZA}=60^{\circ}$, and a seasonally varying SZA case: SZA $=$ Solar Noon. The brown and green arrows indicate the minimum greenness period (when vegetation indices (VIs) are minimum within a growing season) and the peak greenness period (when VIs are maximum within a growing season) respectively. Data from this period will be used to assess the sensitivities of VIs to SZA variations in relation to phenological stages.

During both phenological stages and across all sites (biome types), NDVI exhibited much stronger dependency to SZA variations than EVI (Figure 6C,D). On average, NDVI sensitivity to SZA was 4.6 (peak greenness period) and 5.1(minimum greenness period) times greater than EVI sensitivity (Figure 6C,D; Table 2). For NDVI, there was a 75\% increase in SZA sensitivity from the peak greenness to the minimum greenness period, with the highest $(130 \%)$ increase observed over the Yanco grassland site (Figure 6C,D). There was also an increasing trend in the difference between NDVI and EVI sensitivities to SZA from forest (NDVI sensitivity is 2.2 times of EVI sensitivity), woodland (3.6 times), to pasture (5.4 times) sites (Figure 6C,D; Table 2).

Table 2. Sensitivity of NDVI and EVI to SZA variations for three sites and two phenological stages. Here both NDVI and EVI has been normalised by $\mathrm{VI}_{\mathrm{S}-20}$ so that sensitivities are comparable between VIs, across sites and between phenological stages.

\begin{tabular}{|c|c|c|c|}
\hline Site & Phenological Stages & $\delta N D V I / \delta S Z A$ & $\delta E V I / \delta S Z A$ \\
\hline \multirow{2}{*}{ Tumbarumba } & Peak Greenness Period & 0.0024 & -0.0012 \\
\hline & Minimum Greenness Period & 0.0038 & 0.0016 \\
\hline \multirow{2}{*}{ Cumberland Plains } & Peak Greenness Period & 0.0032 & -0.0016 \\
\hline & Minimum Greenness Period & 0.0042 & 0.0005 \\
\hline \multirow{2}{*}{ Yanco } & Peak Greenness Period & 0.0034 & -0.0003 \\
\hline & Minimum Greenness Period & 0.0077 & 0.0017 \\
\hline
\end{tabular}

\subsection{Sun-Angle Effect on Vegetation Phenology at Site Level}

Figure 7 presents the SSA-reconstructed VI time series normalised to different SZAs. The phenological transitional dates retrieved from each time series were also labelled on the plot. Figure 7 clearly shows that the sun-angle effect on individual observations was propagated across time due to the interaction of seasonal sun-angle variations and vegetation structural change, leading to alternations in both the shape and magnitude of VI temporal profiles (Figure 7). The effect not only caused difference between $\mathrm{VI}_{\mathrm{S}-40}$ or $\mathrm{VI}_{\mathrm{S}-60}$ (seasonally constant $\mathrm{SZA}$ cases) and $\mathrm{VI}_{\mathrm{S}-\mathrm{LSN}}$ (seasonally 
varying SZA cases), but also between the two constant SZA cases $\mathrm{VI}_{\mathrm{S}-40}$ and $\mathrm{VI}_{\mathrm{S}-60}$ (Figure 7). Therefore, VIs with SZA normalised to local solar noon, which is the common input to many global and regional phenology products, do not necessarily align with phenology profiles generated from VIs that were normalised to constant SZA (Figure 7).
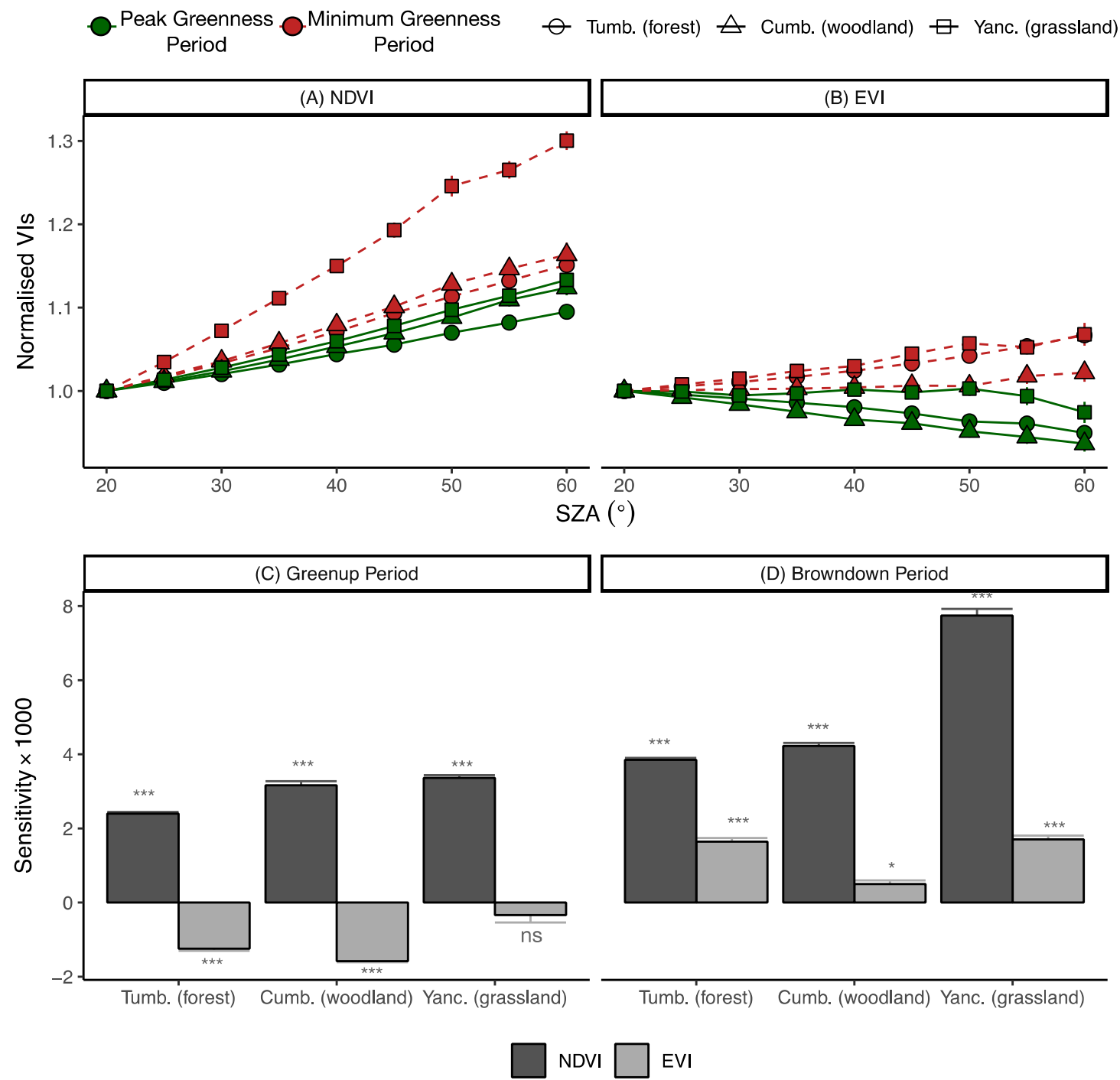

Figure 6. Sensitivity of VIs to SZA variations. (A,B) Changes in NDVI and EVI with variations in SZA from $20^{\circ}$ to $60^{\circ}$ (by every $5^{\circ}$ ) during the peak greenness period and the minimum greenness period respectively, at three local sites; (C,D) Comparison of the sensitivity of NDVI and EVI to changes in SZA during different phenological stages. For comparison among sites, VI values have been normalised by $\mathrm{VI}_{\mathrm{SZA} 20}$ for each site. Sensitivity is defined as change in VI per degree change in SZA. Error bars on the plot indicate $95 \%$ confidence interval of the mean and the statistical significance of the slope is indicated as follows: "***" ( $p<0.0001)$, "**" ( $<$ < 0.01), "ns" (non-significant, p > 0.05). \.

Figure 8 presents the cross-site relationships between phenological transitional dates retrieved from $\mathrm{VI}_{\mathrm{S}-40}$ time series (x-axis, used as a reference) and those retrieved from $\mathrm{VI}_{\mathrm{S}-60}$ or $\mathrm{VI}_{\mathrm{S}-\mathrm{LSN}}$ time series (y-axis). Overall, seasonal sun-angle variations introduced non-negligible uncertainties on phenological transitional dates retrieved from NDVI and EVI. For NDVI, the uncertainties (RMSE) of using time series of NDVI $_{\text {S-LSN }}$ for retrieving SGS, PGS, EGS, and LGS, as compared to the use of $\mathrm{NDVI}_{\mathrm{S}-40}$, were 7.5, 3.7, 6.5, and 11.3 days respectively (Figure 8A-D). The equivalent uncertainties for 
EVI were $10.4,11.9,6.5$, and 8.4 days (Figure 8E-H). Difference in phenology retrievals between two constant SZA cases can be also observed (Figure 8 ).

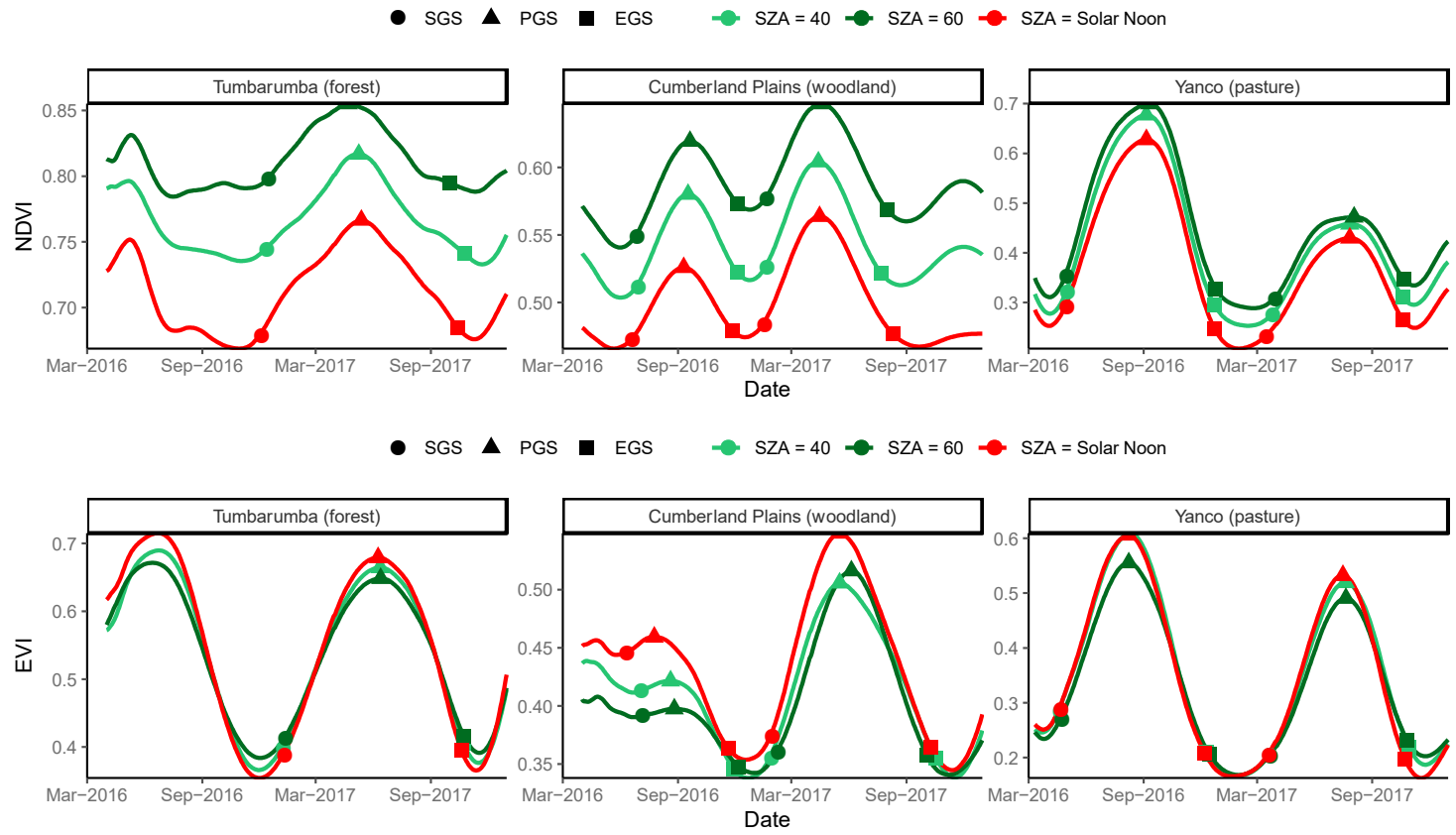

Figure 7. Time series of NDVI and EVI at different SZAs at three local sites sites. Phenological transition dates are indicated on each time series, including the start of growing season (SGS, solid circle), the peak of growing season (PGS, solid triangle), and the end of growing season (EGS $<$ solid rectangle).
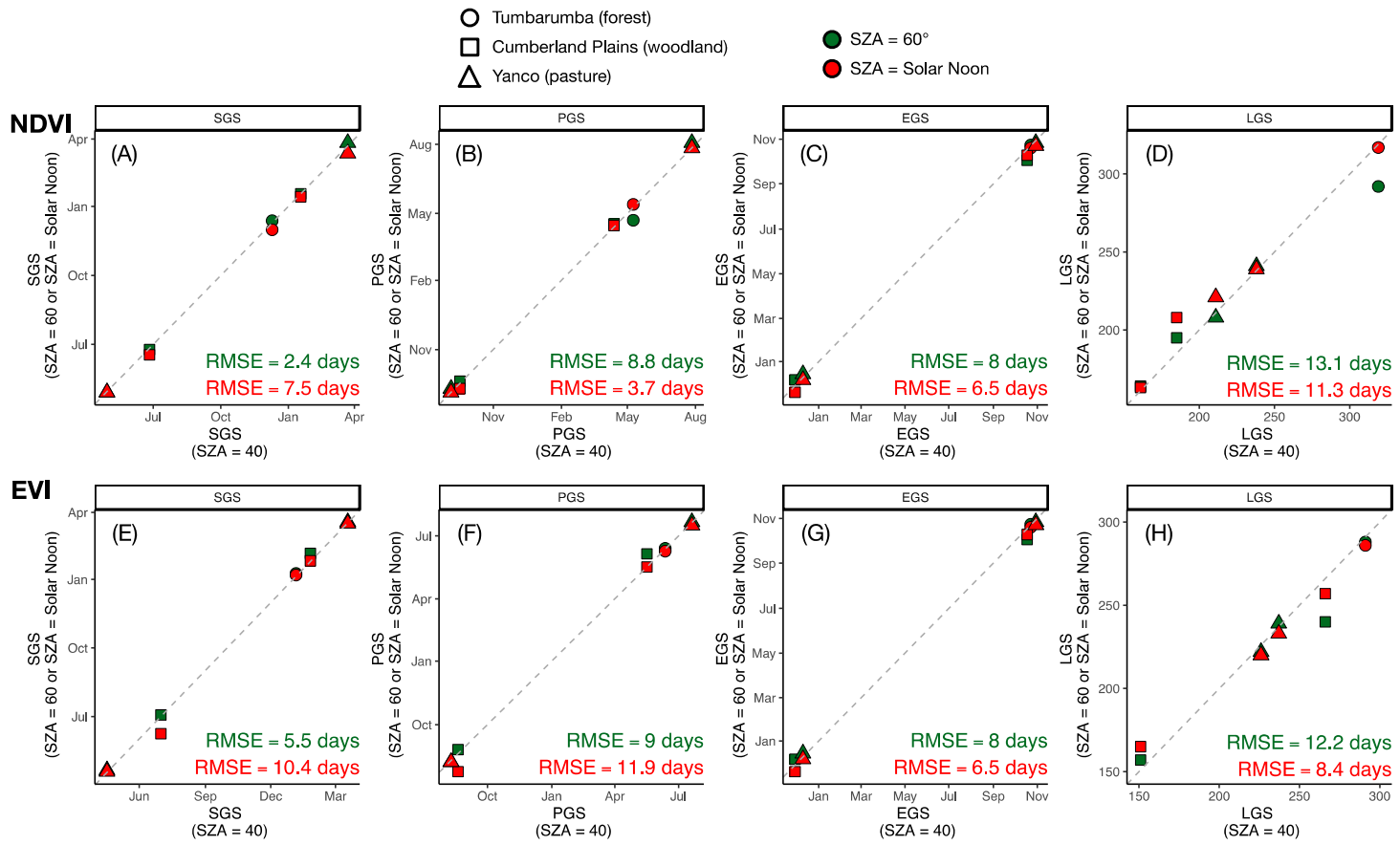

Figure 8. Cross-site comparison between the phenological transitional dates extracted from NDVI and EVI with different SZA configurations at three local sites. (A-D) SGS, PGS, EGS, and LGS extracted from NDVI; (E-H) SGS, PGS, EGS, and LGS extracted from EVI. SGS: Start of Growing Season; PGS: Peak of Growing Season; EGS: End of Growing Season; LGS: Length of Growing Season. 
Figure 9 shows the cross-site comparisons between $\mathrm{VI}_{\max }$ (seasonal maximum VI) and IntVI (annual integrated $\mathrm{VI}$ ), retrieved from time series of $\mathrm{VI}_{\mathrm{S}-40}$ (x-axis, used as a reference) and those retrieved from time series of $\mathrm{VI}_{\mathrm{S}-60}$ or $\mathrm{VI}_{\mathrm{S} \text {-LSN }}$ (y-axis). As expected from a positive NDVI response to the increase in SZA, NDVI $\mathrm{maxS}_{\text {-LSN }}$ and IntNDVI $\mathrm{S}_{\mathrm{SSN}}$ were on average $7 \%$ and $12 \%$ lower than $\mathrm{NDVI}_{\operatorname{maxS}-40}$ and IntNDVI $\mathrm{S}_{-40}$, respectively (Figure 9A). These uncertainties were smaller for EVI, with EVI $_{\text {maxS-LSN }}$ and IntEVI S-LSN $_{\text {were on average }} \%$ and $2 \%$ higher, than EVI $_{\text {maxS-LSN }}$ and IntEVIS-LSN respectively (Figure 9C).

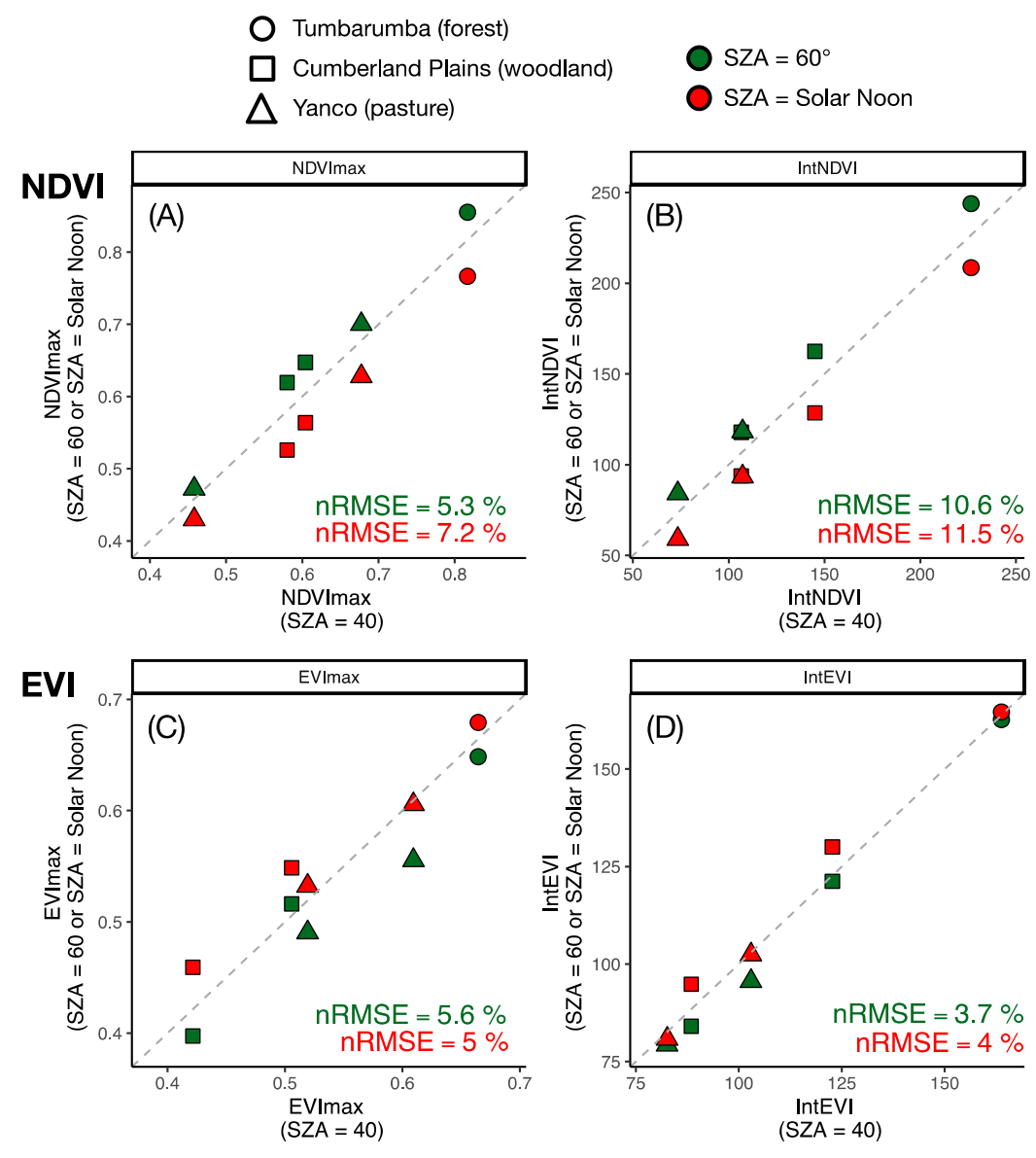

Figure 9. Cross-site relationship of annual peak VI ( $\left.\mathrm{VI}_{\max }\right)$ and annual integrated VI (IntVI) computed from NDVI and EVI with different SZA configurations at three local sites. (A,B) NDVI max $_{\text {and IntNDVI; }}$ (C,D) EVI $_{\max }$ and IntEVI.

As a result of the differential sensitivity of VIs to SZA among sites (biome types), the between-sites relative differences in $\mathrm{VI}_{\max }$ or IntVI were altered by the sun-angle effect. For instance, IntNDVI $\mathrm{S}_{-40}$ for Tumbarumba forest site was on average 151\% higher than that of the Yanco pasture site. However, such differences increased to $174 \%$ if using IntNDVI ${ }_{\text {S-LSN }}$ (Table 3). This change could be ignored for EVI, with IntEVI $\mathrm{S}_{-40}$ and IntEVI $\mathrm{S}_{\mathrm{S} \text { LSN }}$ for Tumbarumba forest site were on average $77 \%$ and $77 \%$ higher than those of Yanco pasture site respectively. Taking the Tumbarumba and Yanco site pair as an example, the estimated distortions in proportion of vegetation productivity between any two sites (or any two pixels), as caused by sun-angle effect alone, was 15\% and 0\% for IntNDVI and IntEVI, respectively (Table 3). 
Table 3. Average $\mathrm{VI}_{\max }$ and IntVI estimated from VI adjusted to different SZA scenarios for three sites.

\begin{tabular}{|c|c|c|c|c|}
\hline Site & Productivity Metrics & SZA Scenarios & NDVI & EVI \\
\hline \multirow{6}{*}{ Tumbarumba } & \multirow{3}{*}{$\mathrm{VI}_{\max }$} & $40^{\circ}$ & 0.82 & 0.66 \\
\hline & & $60^{\circ}$ & 0.86 & 0.65 \\
\hline & & Solar Noon & 0.77 & 0.68 \\
\hline & \multirow{4}{*}{ IntVI } & $40^{\circ}$ & 226.54 & 163.77 \\
\hline & & $60^{\circ}$ & 243.87 & 162.66 \\
\hline & & Solar Noon & 208.56 & 164.63 \\
\hline \multirow{6}{*}{ Cumberland Plains } & & $40^{\circ}$ & 0.59 & 0.46 \\
\hline & \multirow{2}{*}{$\mathrm{VI}_{\max }$} & $60^{\circ}$ & 0.63 & 0.46 \\
\hline & & Solar Noon & 0.54 & 0.50 \\
\hline & \multirow{4}{*}{ IntVI } & $40^{\circ}$ & 125.72 & 105.58 \\
\hline & & $60^{\circ}$ & 140.12 & 102.62 \\
\hline & & Solar Noon & 111.19 & 112.42 \\
\hline \multirow{6}{*}{ Yanco } & & $40^{\circ}$ & 0.57 & 0.56 \\
\hline & \multirow{3}{*}{$\mathrm{VI}_{\max }$} & $60^{\circ}$ & 0.59 & 0.52 \\
\hline & & Solar Noon & 0.53 & 0.57 \\
\hline & & $40^{\circ}$ & 90.32 & 92.76 \\
\hline & \multirow[t]{2}{*}{ IntVI } & $60^{\circ}$ & 101.22 & 87.47 \\
\hline & & Solar Noon & 76.21 & 91.63 \\
\hline
\end{tabular}

\section{Discussion}

In this study we investigated the influence of seasonal sun-angle variations on the temporal VI profiles and phenology retrievals by coupling measurements taken by $\mathrm{H}-8$ geostationary satellite and BRDF modelling. Our results showed that NDVI was more sensitive to SZA than EVI, and such sensitivity varies between biome types and phenological stages. The sun-angle effect that propagated into the VI time series not only introduced large uncertainties in retrieving phenological transitional dates, but also led to errors in estimating vegetation productivity. These results call for an urgent need to take into account sun-angle effects on monitoring vegetation dynamics and phenology using satellite observations. Our results also demonstrated that the sensors onboard the new generation GEO satellites, with refined radiometric and spatial resolutions and augmented by a much denser temporal (angular) sampling than LEO satellites, offer important opportunities to enhance global vegetation monitoring applications.

\subsection{Sun-Angle Dependency of Vegetation Indices (VIs)}

Differential sensitivities to sun-angle variations between VIs, over phenological stages, and across biome types were observed, which highlighted the complexity of the sun-angle effect in the remote sensing of vegetation. Our findings of a strong sun-angle NDVI dependency was largely consistent to what was reported in previous studies $[16,28,77]$. The large SZA sensitivity of NDVI can be attributed to the fact that NDVI is functionally more related to red band reflectance. Due to its high canopy absorption, the red reflectance has a low canopy transmittance, resulting in a more prominent shadow effect, rendering the red reflectance being more sensitive to the changes in Sun (illumination) angle than NIR reflectance which has a high canopy transmittance.

Overall, NDVI was found to be several times more sensitive to sun-angle variations than EVI. This result is consistent with previous findings in Australian tropical forests [25] and savannas [28], but different from what was reported over Amazon tropical forests [26]. Galvão et al. found that NDVI was not as responsive to sun-angle variations as EVI over Amazon forests [26]. These apparently conflicting conclusions might be reconciled with the following reasoning. First, it is well-known that NDVI tends to respond to changes in vegetation biomass in a nonlinear manner and saturate over high biomass areas [13]. Previous studies have found that there was a decreasing trend in NDVI sensitivity to sun-angle with the increase in leaf area index [78] or site-average greenness [28], implies that the muted response of NDVI to sun-angle variations as was observed by [26] was likely due to the fact 
that NDVI was simply saturated over these high biomass areas. Though more careful investigations are needed to confirm our speculation. Second, the behaviour of NDVI with sun-angle variations was found to be dependent on the reflectance properties of underlying soil [17], and such soil-induced effect would be minimal over dense canopies, additionally explained the reduced sensitivity of NDVI to sun-angle variations over dense Amazonian tropical forests. Nonetheless, these studies highlighted the need to assess the sun-angle effect on VIs more systematically across a broad spectrum of vegetation structural classes and geographic regions to draw a general conclusion and more importantly, to reveal the many underlying factors that dictate the sun-angle dependency of VIs and their relative importance at different occasions.

\subsection{Sun-Angle Effect on Retrievals of Vegetation Phenology and Productivity}

It is well-known that sun-angle variations can alter reflectances and VIs, however, it is much less well known the extent to which such effects would be propagated to the retrievals of vegetation phenology parameters, primary productivity, among other biophysical and biochemical properties of vegetation. This is likely because the commonly used LEO satellites can only take 1-2 measurements within a day (or even less frequent if spatial resolution is higher), limiting their ability to sample a wide range of sun-angles. Common practice for studying or correcting sun-angle effect on VIs from LEO involved the use of BRDF models and measurements taken over 8- to 16-day periods, assuming that surface anisotropy would remain unchanged within that interval of time [11,28,78-80]. An apparent shortcoming of this approach is that an intrinsic uncertainty is imposed by the model assumptions, especially for time-sensitive metrics such as phenological transitional dates. Such shortcomings can be circumvented by the use of measurements from GEO satellites, from which a BRDF model can be inverted on a daily basis and the assumption of a constant surface anisotropy within several days is no longer needed. This enabled the assessment of sun-angle effect on phenology retrieval at finer temporal scales, a major benefit of using GEO.

The sun-angle effect alone caused more than one week of uncertainty in retrieving most phenological metrics. Our results using H-8 are largely consistent to a recent study using MODIS over tropical savannas [28] and add more biome types. Furthermore, we showed that the sun-angle effect can introduce $7 \%$ and $10 \%$ uncertainty in estimating $\mathrm{NDVI}_{\max }$ and IntNDVI, and a reduced uncertainty for EVI. This result has important implications as both the $\mathrm{VI}_{\max }$ and IntVI have been used extensively for estimating vegetation primary productivity (or crop yield and rangeland forage production) [81-85], for land carbon uptake modelling [86,87], and for food security assessment for famine early-warning systems [88,89]. Our findings therefore stress the need to consider proper corrections of the sun-angle effect to achieve more reliable use of vegetation indices in a variety of applications.

\subsection{Limitations and Future Perspectives}

The results from this study confirmed that GEO satellites with their advanced temporal and angular sampling offer unprecedented opportunities to better quantify the sun-angle effect on the remote sensing of vegetation dynamics. Nonetheless, several limitations of the existing approach can still be identified. These limitations call for innovations in satellite data collection strategies and sun-angle correction algorithms from the remote-sensing community on one hand, and on the other hand call for user community attention to more carefully examine the relevance of the sun-angle effect on their specific applications.

The first limitation of using GEO satellites is the under-sampling of view angles. By contrast with LEO satellites such as EOS-Terra/Aqua which are limited in both view/sun-angle sampling at any given day, GEO satellites can scan the entire disk more frequently within a day and hence offer much improved sub-daily sampling of sun-angle. However, this sampling comes with the tradeoff of having only a single view angle for any given location. A few potential technical pathways to overcome this limitation can be considered. First, with the assumption of BRDF reciprocity, the RTLSR model can be inverted by interchanging Sun and view geometry [33], allowing varying Sun angles from GEO 
to be used to fill view angle gaps. Another potential pathway, although it has yet to be tested, is the combined use of measurements taken by two or more GEO platforms located at different longitudes which gives at least two view angles for any given location, or even combining the measurements from GEO and LEO platforms. Of course, the second pathway demands many efforts in inter-calibrating measurements taken by multiple sensors [90], which is currently a rapidly developing field [91-93].

The second limitation of the existing approach for normalising sun-angle, not limited to this study, is the reliance on a BRDF model and hence the results obtained have an intrinsic dependency on the model's assumptions. Indeed, it is possible to select measurements taken by GEO to form a time series of reflectance or VI of constant SZA. However, uncertainty would still be introduced into the time series due to seasonally varying solar azimuth angle, in addition to the spatial variations in view-geometry. Only for regions that are located directly underneath the GEO platform (e.g., for H-8, the Papua New Guinea), where time series of VIs with a constant SZA at nadir view angle can be empirically formed without the reliance on a model. Theoretically speaking, unless there are sufficient near-nadir measurements for any given location/date, possibly from multiple narrow FOV (field of view) sensors onboard satellites such as Landsat, from which both solar zenith and azimuth angles can be fixed across time, otherwise it would be very difficult, if not impossible, to empirically correct the sun-angle effect. Even with this kind of data, higher latitude would still present a great challenge due to the very low maximum daily sun-angle in wintertime, forcing the selection of observations made at large SZA deemed to be less reliable.

Two technical directions can be taken to address the second limitation. First, from an observation point of view, studies can take advantage of increasingly available GEO data to assess the relative sensitivity of reflectances and VIs to SZA and RAA variations in relation to biome types and phenological stages. Conclusions drawn from these studies can be used to make decisions whether constant SZA or constant RAA is to be targeted (as the two cannot be fixed in the same time). A conceptually similar approach was proposed recently to match GEO (H-8 AHI) and LEO (Terra MODIS) based on the criteria of equal SZA or equal RAA [93]. Second, from a modelling point of view, the inversion of more complicated 3-D radiative-transfer models may become feasible with the combined use of high-resolution spaceborne light-detection and ranging (LiDAR, e.g., those from NASA's Global Ecosystem Dynamics Investigation, or GEDI mission), multi-spectral / multi-angle measurements, from which a more reliable surface reflectance correction for BRDF effect can be achieved.

The third limitation is the direct ground validation of the BRDF model simulated reflectance. Indeed, it is a great challenge to obtain ground measurements at different sun-view geometries at the field size comparable to the size of satellite pixels (e.g., $1 \mathrm{~km}$ for $\mathrm{H}-8 \mathrm{AHI}$ ). Besides, normalising SZA to a constant value, e.g., $45^{\circ}$, implies that for mid-/high-latitude there would essentially be no available real observations at such a SZA during the winter time (as the sun never reaches those SZAs in the winter for mid-/high-latitude). Ground-truth measurements would be relatively easier to make by comparing to high-resolution satellite measurements, but the dilemma here is that a high-resolution satellite means narrower FOV and hence even less frequent revisits and measurements for BRDF model inversion.

Given these dilemmas, alternative and indirect validation strategies may be taken to get around the validation challenge. The first strategy is to take multi-angle measurements using unmanned aerial vehicles (UAVs) over the relatively homogeneous area to obtain vegetation BRDF [94]. These measurements can be used to study the sun-view geometry effect on VIs and their temporal dynamics at small scale directly, but can also be used to compare to VIs normalised to defined sun-view geometry based on satellite measurements. The second strategy is to use the measurements from rapid developing global eddy-covariance flux tower networks, from which canopy structure (e.g., photosynthetic capacity) and function (e.g., Gross Primary Productivity, GPP) can be derived at the footprint size comparable to the size of moderate spaceborne sensors (e.g., $100 \mathrm{~m}-1000 \mathrm{~m}$ ) [95,96]. Satellite and flux tower measurements have been frequently used for monitoring ecosystem dynamics [96-104]. The attempts of verifying the temporal vegetation dynamics as observed from satellites have also 
been made $[32,67,100,105]$. Additionally, measurements taken by more cost-effective time-lapse multispectral phenology-cameras (or phenocam), that now are widely installed on flux towers and other ecological monitoring sites can also serve as ground verification data [106-110].

Indeed, all the aforementioned challenges in normalising sun-angle variations with satellite observations originated by the inability of satellites to maneuver to a variety of positions relative to the sun. Much efforts are urgently needed to refine our understanding of the interactions between sun-angle variations, vegetation phenology, canopy structure, among many other external factors. Aside from the methodological development and the increasingly available large amount of data from space, it is perhaps equally important to reflect back on an early question asked by Middleton in 1992: "which solar zenith angle was best for acquiring surface reflectance measurements in order to estimate canopy variables?" [18].

\section{Conclusions}

Here we evaluated the sun-angle effect on vegetation indices and phenology retrievals from time series of VIs using H-8 AHI geostationary satellite measurements. Our results revealed that spatiotemporal sun-angle variations can pose many challenges to resolving vegetation dynamics by introducing considerable uncertainties in phenological metrics retrievals. Future studies are urgently needed to assess the relevance of the sun-angle effect on retrievals of biophysical and ecosystem function variables from remote-sensing measurements. Only through continuous investigations on how sun-angle variations affect spatiotemporal vegetation dynamics and what is the best strategy to deal with it, can we achieve a more quantitative remote sensing of true signals of vegetation change across the entire globe and through time.

Author Contributions: Conceptualization, X.M. and A.H.; methodology, X.M. and N.N.T.; software, X.M. and N.N.T.; validation, X.M. and N.N.T.; formal analysis, X.M.; investigation, all co-authors; resources, X.M. and A.H.; data curation, X.M. and N.N.T.; writing—original draft preparation, X.M.; writing—review and editing, all co-authors; visualization, X.M.; supervision, X.M.; project administration, X.M.; funding acquisition, X.M. and A.H. All authors have read and agreed to the published version of the manuscript.

Funding: This research was funded by the "Research Startup Funding for Youth Professor" granted to X.M. by Lanzhou University and the AusCover - Landscapes Land Surface Phenology product development and maintenance funding granted to A.H. by Australian Terrestrial Ecosystem Research Network (TERN).

Acknowledgments: The authors would like to thank the anonymous reviewers for their valuable comments to improve the quality of the paper. The authors would like to thank BoM (Bureau of Meteorology, Australia) for providing the atmospherically corrected H-8 AHI data.

Conflicts of Interest: The authors declare no conflict of interest.

\section{References}

1. Pinter, P.J.; Zipoli, G.; Maracchi, G.; Reginato, R.J. Influence of topography and sensor view angles on NIR/red ratio and greenness vegetation indices of wheat. Int. J. Remote Sens. 1987, 8, 953-957. [CrossRef]

2. Huete, A.R. A Soil-Adjusted Vegetation Index (SAVI). Remote Sens. Environ. 1988, 25, 295-309. [CrossRef]

3. Kaufman, Y.J.; Tanré, D. Atmospherically Resistant Vegetation Index (ARVI) for EOS-MODIS. IEEE Trans. Geosci. Remote Sens. 1992, 30, 261-270. [CrossRef]

4. Sellers, P.J.; Tucker, C.J.; Collatz, G.J.; Los, S.O.; Justice, C.O.; Dazlich, D.A.; Randall, D.A. A revised land surface parameterizaton (SiB-2) for atmospheric GCMs. Part 2: The generation of global fields of terrestrial biophysical parameters from satellite data. J. Clim. 1996, 9, 706-737. [CrossRef]

5. Los, S.O.; North PR, J.; Barnsley GM, J. A methood to convert AVHRR Normalized Difference Vegetation Index time series to a standard viewing and illumination geometry. Remote Sens. Environ. 2005, 99, 400-411. [CrossRef]

6. Kobayashi, H.; Dye, D.G. Atmospheric conditions for monitoring the long-term vegetation dynamics in the Amazon using normalized difference vegetation index. Remote Sens. Environ. 2005, 97, 519-525. [CrossRef] 
7. Ren, H.; Zhou, G.; Zhang, F. Using negative soil adjustment factor in soil-adjusted vegetation index (SAVI) for aboveground living biomass estimation in arid grassland. Remote Sens. Environ. 2018, 209, 439-445. [CrossRef]

8. Zhang, Z.; Zhang, Y.; Joiner, J.; Migliavacca, M. Angle matters: Bidirectional effects impact the slope of relationship between gross primary productivity and sun-induced chlorophyll fluorescence from Orbiting Carbon Observatory-2 across biomes. Glob. Chang. Biol. 2018, 24, 5017-5020. [CrossRef]

9. Jin, Y.; Schaaf, C.B.; Woodcock, C.E.; Gao, F.; Li, X.; Strahler, A.H. Consistency of MODIS surface bidirectional reflectance distribution function and albedo retrievals: 2. Validation. J. Geophys. Res. 2003, 108. [CrossRef]

10. Gao, F.; He, T.; Masek, J.G.; Shuai, Y.; Schaaf, C.B.; Wang, Z. Angular effects and correction for medium resolution sensors to support crop monitoring. IEEE J. Sel. Top. Appl. Earth Obs. Remote Sens. 2014, 7, 4480-4489. [CrossRef]

11. Bi, J.; Knyazikhin, Y.; Choi, S.; Park, T.; Barichvich, J.; Ciais, P.; Fu, R.; Ganguly, S.; Hall, F.; Hilker, T.; et al. Sunlight mediated seasonality in canopy structure and photosynthetic activity of Amazonian rainforests. Environ. Res. Lett. 2015, 10, 064014. [CrossRef]

12. Vermote, E.F.; El Saleous, N.Z.; Justice, C.O. Atmospheric correction of MODIS data in the visible to middle infrared: First results. Remote Sens. Environ. 2002, 83, 97-111. [CrossRef]

13. Huete, A.; Didan, K.; Miura, T.; Rodriguez, E.P.; Gao, X.; Ferreira, L.G. Overview of the radiometric and biophysical performance of the MODIS vegetation indices. Remote Sens. Environ. 2002, 83, 195-213. [CrossRef]

14. Schaaf, C.B.; Gao, F.; Strahler, A.H.; Lucht, W.; Li, X.; Tsang, T.; Strugnell, N.C.; Zhang, X.; Jin, Y.; Muller, J.-P.; et al. First operational BRDF, albedo, nadir reflectance products from MODIS. Remote Sens. Environ. 2002, 83, 135-148. [CrossRef]

15. Cowell, J.E. Vegetation canopy reflectance. Remote Sens. Environ. 1974, 3, 175-183. [CrossRef]

16. Pinter, P.J.; Jackson, R.D.; Idso, S.B. Diurnal patterns of wheat spectral reflectances. IEEE Trans. Geosci. Remote Sens. 1983, 21, 156-163. [CrossRef]

17. Huete, A.R. Soil and sun-angle interactions on partial canopy spectra. Int. J. Remote Sens. 1987, 8, 1307-1317. [CrossRef]

18. Middleton, E.M. Solar zenith angle effects on vegetation indices in tallgrass prairie. Remote Sens. Environ. 1991, 38, 45-62. [CrossRef]

19. Walter-Shea, E.A.; Biehl, L.L. Measuring vegetation spectral properties. Remote Sens. Rev. 1990, 5, $179-205$. [CrossRef]

20. van Leeuwen, W.J.D.; Huete, A.R.; Laing, T.W. MODIS vegetation index compositing approach: A prototype with AVHRR data. Remote Sens. Environ. 1999, 69, 264-280. [CrossRef]

21. Petri, C.A.; Galvão, L.S. Sensitivity of seven MODIS vegetation indices to BRDF effects during the Amazonian dry season. Remote Sens. 2019, 11, 1650. [CrossRef]

22. Schaaf, C.B.; Strahler, A.H. Solar zenith angle effects on forest canopy hemispherical reflectances calculated with a geometric-optical bidirectional reflectance model. IEEE Trans. Geosci. Remote Sens. 1993, 31, 921-927. [CrossRef]

23. Tucker, C.J.; Pinzon, J.E.; Brown, M.E.; Slayback, D.A.; Pak, E.W.; Mahoney, R.; Vermote, E.F.; El Saleous, N. An extended AVHRR 8-km NDVI dataset compatible with MODIS and SPOT vegetation NDVI data. Int. J. Remote Sens. 2005, 26, 4485-4498. [CrossRef]

24. Uprety, S.; Cao, C. Suomi NPP VIIRS reflective solar band on-orbit radiometric stability and accuracy assessment using desert and Antarctic Dome C sites. Remote Sens. Environ. 2015, 166, 106-115. [CrossRef]

25. Bhandari, S.; Phinn, S.; Gill, T. Assessing viewing and illumination geometry effects on the MODIS vegetation index (MOD13Q1) time series: Implications for monitoring phenology and disturbances in forest communities in Queensland, Australia. Int. J. Remote Sens. 2014, 32, 7513-7538. [CrossRef]

26. Galvão, L.S.; Breunig, F.M.; dos Santos, J.R.; de Moura, Y.M. View-illumination effects on hyperspectral vegetation indices in the Amazonian tropical forest. Int. J. Appl. Earth Obs. Geoinf. 2013, 21, 291-300. [CrossRef]

27. Morton, D.C.; Nagol, J.; Carabajal, C.C.; Rosette, J.; Palace, M.; Cook, B.D.; Vermote, E.F.; Harding, D.J.; North, P.R.J. Amazon forests maintain consistent canopy structure and greenness during the dry season. Nature 2014, 506, 221-224. [CrossRef] 
28. Ma, X.; Huete, A.; Tran, N.N. Interaction of seasonal sun-angle and savanna phenology observed and modelled using MODIS. Remote Sens. 2019, 11, 1398. [CrossRef]

29. Huete, A.R.; Didan, K.; Shimabukuro, Y.E.; Ratana, P.; Saleska, S.R.; Hutyra, L.R.; Yang, W.; Nemani, R.R.; Myneni, R. Amazon rainforests green-up with sunlight in dry season. Geophys. Res. Lett. 2006, 33. [CrossRef]

30. Maeda, E.E.; Heiskanen, J.; Aragão, L.E.O.C.; Rinne, J. Can MODIS EVI monitor ecosystem productivity in the Amazon rainforest? Geophys. Res. Lett. 2014, 41, 7176-7183. [CrossRef]

31. Saleska, S.R.; Wu, J.; Guan, K.; Araujo, A.C.; Huete, A.; Nobre, A.D.; Restrepo-Coupe, N. Dry-season greening of Amazon forests. Nature 2016, 531, E4-E5. [CrossRef] [PubMed]

32. Wu, J.; Albert, L.P.; Lopes, A.P.; Restrepo-Coupe, N.; Hayek, M.; Wiedemann, K.T.; Guan, K.; Stark, S.C.; Christoffersen, B.; Prohaska, N.B.; et al. Leaf development and demography explain photosynthetic seasonality in Amazon evergreen forests. Science 2016, 351, 972-976. [CrossRef] [PubMed]

33. Proud, S.R.; Zhang, Q.; Schaaf, C.; Fensholt, R.; Rasmussen, M.O.; Shisanya, C.; Mutero, W.; Mbow, C.; Anyamba, A.; Pak, E.; et al. The normalization of surface anisotropy effects present in SEVIRI reflectances by using the MODIS BRDF method. IEEE Trans. Geosci. Remote Sens. 2014, 52, 6026-6039. [CrossRef]

34. Fensholt, R.; Sandholt, I.; Stisen, S.; Tucker, C. Analysing NDVI for the African continent using the geostationary meteosat second generation SEVIRI sensor. Remote Sens. Environ. 2006, 101, 212-229. [CrossRef]

35. Sobrino, J.A.; Julien, Y.; Sòria, G. Phenology estimation from Meteosat second generation data. IEEE J. Sel. Top. Appl. Earth Obs. Remote Sens. 2013, 6, 1653-1659. [CrossRef]

36. Guan, K.; Medvigy, D.; Wood, E.F.; Caylor, K.K.; Li, S.; Jeong, S.J. Deriving vegetation phenological time and trajectory information over Africa using SEVIRI daily LAI. IEEE Trans. Geosci. Remote Sens. 2013, 52, 1113-1130. [CrossRef]

37. Yan, D.; Zhang, X.; Yu, Y.; Guo, W. A comparison of tropical rainforest phenology retrieved from geostationary (SEVIRI) and polar-orbiting (MODIS) sensors across the Congo Basin. IEEE Trans. Geosci. Remote Sens. 2016, 54, 4867-4881. [CrossRef]

38. Xie, Q.; Dash, J.; Huete, A.; Jiang, A.; Yin, G.; Ding, Y.; Peng, D.; Hall, C.C.; Brown, L.; Shi, Y.; et al. Retrieval of crop biophysical parameters from Sentinel-2 remote sensing imagery. Int. J. Appl. Earth Obs. Geoinf. 2019, 80, 187-195. [CrossRef]

39. Kalluri, S.; Daniels, J.; Gunshor, M.; Lindsey, D.; Schmit, T.; Wu, X. The First Year of Advanced Baseline Imager. In Proceedings of the 2018 IEEE International Geoscience and Remote Sensing Symposium, Valencia, Spain, 22-27 July 2018.

40. Zhang, Q.; Zhang, Y.; Li, Z.; Li, J.; Zhang, X. The effects of sun-viewer geometry on sun-induced fluorescence and its relationship with gross primary production. In Proceedings of the 2019 IEEE International Geoscience and Remote Sensing Symposium, Yokohama, Japan, 28 July-2 August 2019.

41. Miura, T.; Nagai, S.; Takeuchi, M.; Ichii, K.; Yoshioka, H. Improved characterisation of vegetation and land surface seasonal dynamics in central Japan with Himawari-8 hypertemporal data. Sci. Rep. 2019, 9, 1-12. [CrossRef]

42. Li, S.; Wang, W.; Hashimoto, H.; Xiong, J.; Vandal, T.; Yao, J.; Qian, L.; Icchi, K.; Lyapustin, A.; Wang, Y.; et al. First provisional land surface reflectance product from geostationary satellite Himawari-8 AHI. Remote Sens. 2019, 11, 2990. [CrossRef]

43. Fang, L.; Zhan, X.; Schull, M.; Kalluri, S.; Laszlo, I.; Yu, P.; Carter, C.; Hain, C.; Anderson, M. Evapotranspiration data product from NESDIS GET-D system upgrated for GOES-16 ABI observations. Remote Sens. 2019, 11, 2639. [CrossRef]

44. Chen, Y.; Sun, K.; Chen, C.; Bai, T.; Park, T.; Wang, W.; Nemani, R.R.; Myneni, R.B. Generation and evaluation of LAI and fPAR products from Himawari-8 Advanced Himawari Imager (AHI) data. Remote Sens. 2019, 11, 1517. [CrossRef]

45. Wheeler, K.I.; Dietz, M.C. A statistical model for estimating midday NDVI from the geostationary operational environmental satellite (GOES) 16 and 17. Remote Sens. 2019, 11, 2507. [CrossRef]

46. Bessho, K.; Date, K.; Hayashi, M.; Ikeda, A.; Imai, T.; Inoue, H.; Kumagai, Y.; Miyakawa, T.; Murata, H.; Ohno, T.; et al. An introduction to Himawari-8/9-Japan's new-generation geostationary meteorological satellites. J. Meteorol. Soc. Jpn. 2016, 94, 151-183. [CrossRef] 
47. Beringer, J.; Hutley, L.B.; McHugh, I.; Arndt, S.K.; Campbell, D.; Cleugh, H.A.; Cleverly, J.; de Dios, V.R.; Eamus, D.; Evans, B. An introduction to the Australian and New Zealand flux tower network-OzFlux. Biogeosciences 2016, 13, 5895-5916. [CrossRef]

48. Lyapustin, A.; Wang, Y.; Laszlo, I.; Hilker, T.; Hall, F.; Sellers, P.; Tucker, C.J.; Korkin, S.V. Multi-Angle Implementation of Atmospheric Correction for MODIS (MAIAC): 3. Atmospheric Correction. Remote Sens. Environ. 2012, 127, 385-393. [CrossRef]

49. Lyapustin, A.; Wang, Y. MAIAC-Multi-Angle Implementation of Atmospheric Correction for MODIS: Algorithm Theoretical Basis Document, v1.0. 2008. Available online: https://ladsweb.modaps.eosdis.nasa. gov/missions-and-measurements/modis/MAIAC_ATBD_v1.pdf (accessed on 27 February 2020).

50. Matsuoka, M.; Honda, R.; Nonomura, A.; Moriya, H.; Akatsuka, S.; Yoshioka, H.; Takagi, M. A method to improve geometric accuracy of Himawari-8/AHI "Japan Area” data. J. Jpn. Soc. Photogramm. Remote Sens. 2016, 54, 280-289.

51. Lucht, W.; Schaaf, C.B.; Strahler, A.H. An algorithm for the retrieval of albedo from space using semiempirical BRDF models. IEEE Trans. Geosci. Remote Sens. 2000, 38, 977-997. [CrossRef]

52. Lucht, W.; Roujean, J.L. Considerations in the parametric modeling of BRDF and albedo from multiangular satellite sensor observations. Remote Sens. Rev. 2000, 18, 343-379. [CrossRef]

53. Roujean, J.L.; Leroy, M.; Deschamps, P.Y. A bidirectional reflectance model of the Earth's surface for the correction of remote sensing data. J. Geophys. Res. 1992, 97, 20455-20468. [CrossRef]

54. Li, X.; Strahler, A.H. Geometric-optical bidirectional reflectance modeling of the discrete crown vegetation canopy: Effect of crown shape and mutual shadowing. IEEE Trans. Geosci. Remote Sens. 1992, 30, $276-292$. [CrossRef]

55. Strahler, A.H.; Lucht, W.; Schaaf, C.B.; Tsang, T.; Gao, F.; Li, X.; Muller, J.P.; Lewis, P.; Barnsley, M.J. MODIS BRDF/Albedo Product: Algorithm Theoretical Basis Document Versin 5.0. 1999. Available online: https://modis.gsfc.nasa.gov/data/atbd/atbd_mod09.pdf (accessed on 31 March 2020).

56. Matsuoka, M.; Takagi, M.; Akatsuka, S.; Honda, R.; Nonomura, A.; Moriya, H.; Yoshioka, H. Bidirectional reflectance modeling of the geostationary sensor Himawari-8/AHI using a kernal-driven BRDF model. ISPRS Ann. Photogramm. Remote Sens. Spat. Inf. Sci. 2016, III-7, 3-8. [CrossRef]

57. Lucht, W.; Hyman, A.H.; Strahler, A.H.; Barnsley, M.J.; Hobson, P.; Muller, J.P. A comparison of satellite-derived spectral albedos to ground-based broadband albedo measurements modeled to satellite spatial scale for a semidesert landscape. Remote Sens. Environ. 2000, 74, 85-98. [CrossRef]

58. Wanner, W.; Li, X.; Strahler, A.H. On the derivation of kernels for kernel-driven models of bidirectional reflectance. J. Geophys. Res. 1995, 100, 21077-21089. [CrossRef]

59. Schaaf, C.B.; Li, X.; Strahler, A.H. Topographic effects on bidirectional and hemispherical reflectances calculated with a geometric-optical canopy model. IEEE Trans. Geosci. Remote Sens. 1994, 32, 1186-1193. [CrossRef]

60. Zhang, X.; Friedl, M.A.; Schaaf, C.B.; Strahler, A.H.; Hodges, J.C.F.; Gao, F.; Reed, B.C.; Huete, A. Monitoring vegetation phenology using MODIS. Remote Sens. Environ. 2003, 84, 471-475. [CrossRef]

61. Beck, P.S.A.; Atzberger, C.; Høgda, K.A.; Johansen, B.; Skidmore, A.K. Improved monitoring of vegetation dynamics at very high latitudes: A new method using MODIS NDVI. Remote Sens. Environ. 2006, 100, 321-334. [CrossRef]

62. Piao, S.; Fang, J.; Zhou, L.; Ciais, P.; Zhu, B. Variations in satellite-derived phenology in China's temperate vegetation. Glob. Chang. Biol. 2006, 12, 672-685. [CrossRef]

63. Tan, B.; Morisette, J.; Wolfe, R.; Gao, F.; Nightingale, J.M.; Pedelty, J.; Ederer, G. User Guide for MOD09PHN and MOD15PHN Version 3.0. 2011. Available online: http://citeseerx.ist.psu.edu/viewdoc/download; jsessionid=416AB95FB7EC158E94B0BB21AFC168F9?doi=10.1.1.492.1979\&rep=rep1\&type=pdf $($ accessed on 27 February 2020).

64. Wu, C.; Gonsamo, A.; Gough, C.M.; Chen, J.M.; Xu, S. Modeling growing season phenology in North American forests using seasonal mean vegetation indices from MODIS. Remote Sens. Environ. 2014, 147, 79-88. [CrossRef]

65. Myneni, R.; Hall, F.; Sellers, P.; Marshak, A. The interpretation of spectral vegetation indices. IEEE Trans. Geosci. Remote Sens. 1995, 33, 481-486. [CrossRef]

66. Huete, A.R.; Glenn, E.P. Remote Sensing of Ecosystem. Adv. Environ. Remote Sens. Sens. Algorithms Appl. 2011, 12, 291-320. 
67. Rouse, J.; Haas, R.; Schell, J.; Deering, D. Monitoring vegetation systems in the Great Plains with ERTS. In Third Earth Resources Technology Satellite Symposium. Technical Presentations, Section A; Freden, S.C., Mercanti, E.P., Becker, M., Eds.; NASA SP-351; National Aeronautics and Space Administration: Washington, DC, USA, 1973; Volume I, pp. 309-317.

68. Ma, X.; Huete, A.; Yu, Q.; Restrepo-Coupe, N.; Davies, K.; Broich, M.; Ratana, P.; Beringer, J.; Hutley, L.B.; Cleverly, J.; et al. Spatial patterns and temporal dynamics in savanna vegetation phenology across the North Australian Tropical Transect. Remote Sens. Environ. 2013, 139, 97-115. [CrossRef]

69. Ma, X.; Huete, A.; Moran, S.; Ponce-Campos, G.; Eamus, D. Abrupt shifts in phenology and vegetation productivity under climate extremes. J. Geophys. Res. Biogeosci. 2015, 120, 1-17. [CrossRef]

70. Wang, D.; Liang, S. Singular spectrum analysis for filling gaps and reducing uncertainties of MODIS Land Products. In Proceedings of the IGARSS 2008-2008 IEEE International Geoscience and Remote Sensing Symposium, Boston, MA, USA, 8-11 July 2008.

71. Aban, J.L.E.; Tateishi, R. Application of Singular Spectrum Analysis (SSA) for the Reconstruction of Annual Phenological Profiles of NDVI Time Series Data. The 24th Proceedings of Asian Association of Remote Sensing, Section 11. Data Processing: Data Fusion. 2004. Available online: https:/a-a-r-s.org/proceeding/ ACRS2004/Papers/DF204-7.htm (accessed on 31 March 2020).

72. Kondrashov, D.; Ghil, M. Spatio-temporal filling of missing points in geophysical datasets. Nonlinear Process. Geophys. 2006, 13, 151-159. [CrossRef]

73. Ponce-Campos, G.; Moran, M.S.; Huete, A.; Zhang, Y.; Bresloff, C.; Huxman, T.E.; Eamus, E.; Bosch, D.D.; Buda, A.R.; Gunter, S.A.; et al. Ecosystem resilience despite large-scale altered hydroclimatic conditions. Nature 2013, 494, 349-352. [CrossRef] [PubMed]

74. Zhang, Y.; Moran, M.S.; Nearing, M.A.; Ponce-Campos, G.E.; Huete, A.R.; Buda, A.R.; Bosch, D.D.; Gunter, S.A.; Kitchen, S.G.; McNab, W.H.; et al. Extreme precipitation patterns and reductions of terrestrial ecosystem production across biomes. J. Geophys. Res. Biogeosci. 2013, 118, 148-157. [CrossRef]

75. Lymburner, A.; Tan, P.; McIntyre, A.; Thankappan, M.; Sixsmith, J. Dynamic Land Cover Dataset Version 2.1. Geoscience Australia, Canberra. 2015. Available online: https:/ecat.ga.gov.au/geonetwork/srv/eng/catalog. search\#/metadata/83868 (accessed on 23 April 2020).

76. R Core Team. R: A Language and Environment for Statistical Computing. In $R$ Foundation for Statistical Computing; R Core Team: Vienna, Austria, 2019.

77. Huete, A.; Liu, H.; van Leeuwen, W. The use of vegetation indices in forested regions: Issues of linearity and saturation. In Proceedings of the 1997 IEEE International Geoscience and Remote Sensing Symposium, Singapore, 3-8 August 1997; pp. 1966-1968.

78. Shuai, Y.; Schaaf, C.; Strahler, A.; Liu, J.; Jiao, Z. Quality assessment of BRDF/albedo retrievals in MODIS operational system. Geophys. Res. Lett. 2008, 35. [CrossRef]

79. de Abelleyra, D.; Verón, S.R. Comparison of different BRDF correction methods to generate daily normalized MODIS $250 \mathrm{~m}$ time series. Remote Sens. Environ. 2014, 140, 46-59. [CrossRef]

80. Wang, Z.; Schaaf, C.B.; Sun, Q.; Shuai, Y.; Román, M.O. Capturing rapid land surface dynamics with Collection V006 MODIS BRDF/NBAR/Albedo (MCD43) products. Remote Sens. Environ. 2018, 207, 50-64. [CrossRef]

81. Liu, J.; Shang, J.; Qian, B.; Huffman, T.; Zhang, Y.; Dong, T.; Jing, Q.; Martin, T. Crop yield estimation using time-series MODIS data and the effects of cropland masks in Ontario, Canada. Remote Sens. 2019, 11, 2419. [CrossRef]

82. Yan, D.; Zhang, X.; Nagai, S.; Yu, Y.; Akitsu, T.; Nasahara, K.N.; Ide, R.; Maeda, T. Evaluating land surface phenology from the Advanced Himawari Imager using observations from MODIS and the Phenological Eyes network. Int. J. Appl. Earth Obs. Geoinf. 2019, 79, 71-83. [CrossRef]

83. Moriondo, M.; Maselli, F.; Bindi, M. A simple model of regional wheat yield based on NDVI data. Eur. J. Agron. 2007, 26, 266-274. [CrossRef]

84. Kern, A.; Barcza, Z.; Marjanović, H.; Árendás, T.; Fodor, N.; Bónis, P.; Bognár, P.; Lichtenberger, J. Statistical modelling of crop yield in Central Europe using climate data and remote sensing vegetation indeices. Agric. For. Meteorol. 2018, 260, 300-320. [CrossRef]

85. Kobayashi, H.; Nagai, S.; Kim, Y.; Yang, W.; Ikeda, K.; Ikawa, H.; Nagano, H.; Suzuki, R. In situ observations reveal how spectral reflectance responds to growing season phenology of an open evergreen forest in Alaska. Remote Sens. 2018, 10, 1071. [CrossRef] 
86. Yuan, W.; Chen, Y.; Xia, J.; Dong, W.; Magliulo, V.; Moors, E.; Olesen, J.E.; Zhang, H. Estimating crop yield using a satellite-based light use efficiency model. Ecol. Indic. 2016, 60, 702-709. [CrossRef]

87. Bhatt, U.S.; Walker, D.A.; Raynolds, M.K.; Bieniek, P.A.; Epstein, H.E.; Comiso, J.C.; Pinzon, J.E.; Tucker, C.J.; Polyakov, I.G. Recent declines in warming and vegetation greening trends over pan-Arctic tundra. Remote Sens. 2013, 5, 4229-4254. [CrossRef]

88. Zhang, X.; Kondragunta, S.; Ram, J.; Schmidt, C.; Huang, H.C. Near-real-time global biomass burning emissions product from geostationary satellite constellation. J. Geophys. Res. Atmos. 2012, 117. [CrossRef]

89. Jin, N.; Tao, B.; Ren, W.; Feng, M.; Sun, R.; He, L.; Zhuang, W.; Yu, Q. Mapping irrigated and rainfed wheat areas using multi-temporal satellite data. Remote Sens. 2016, 8, 207. [CrossRef]

90. Chander, G.; Hewison, T.J.; Fox, N.; Wu, X.; Xiong, X.; Blackwell, W.J. Overview of intercalibration of satellite instruments. IEEE Trans. Geosci. Remote Sens. 2013, 51, 1056-1080. [CrossRef]

91. Fan, X.; Liu, Y. Multisensor Normalised Difference Vegetation Index intercalibration: A comprehensive overview of the causes of and solutions for multisensor differences. IEEE Geosci. Remote Sens. Mag. 2018, 6, 23-45. [CrossRef]

92. Qin, Y.; McVicar, T.R. Spectral band unification and inter-calibration of Himawari AHI with MODIS and VIIRS: Constructing virtual dual-view remote sensors from geostationary and low-Earth-orbiting sensors. Remote Sens. Environ. 2018, 209, 540-550. [CrossRef]

93. Adachi, Y.; Kikuchi, R.; Obata, K.; Yoshioka, H. Relative Azimuthal-Angle Matching (RAM): A screening method for GEO-LEO reflectance comparison in middle latitude forests. Remote Sens. 2019, 11, 1095. [CrossRef]

94. Grenzdöffer, G.J.; Niemeyer, F. UAV based BRDF-measurements of agricultural surfaces with PFIFFIkus. Int. Arch. Photogramm. Remote Sens. Spat. Inf. Sci. 2011, 38, 229-234.

95. Baldocchi, D.; Falge, E.; Gu, L.; Olson, R.; Hollinger, D.; Running, S.; Anthoni, P.; Bernhofer, C.; Davis, K.; Evans, R.; et al. FLUXNET: A new tool to study the temporal and spatial variability of ecosystem-scale carbon dioxide, water vapor, and energy flux densities. Bull. Am. Meteorol. Soc. 2001, 82, 2415-2434. [CrossRef]

96. Aubinet, M.; Vesala, T.; Papale, D. (Eds.) Eddy Covariance: A Practical Guide to Measurement and Data Analysis; Springer: Berlin/Heidelberg, Germany, 2012.

97. Leuning, R.; Cleugh, H.A.; Zegelin, S.J.; Hughes, D. Carbon and water fluxes over a temperate Eucalyptus forest and a tropical wet/dry savanna in Australia: Measurements and comparison with MODIS remote sensing estimates. Agric. For. Meteorol. 2005, 129, 151-173. [CrossRef]

98. Cescatti, A.; Marcolla, B.; Santhana Vannan, S.K.; Pan, J.K.; Román, M.O.; Yang, X.; Ciais, P.; Cook, R.B.; Law, B.E.; Matteucci, G.; et al. Intercomparison of MODIS albedo retrievals and in situ measurements across the global FLUXNET network. Remote Sens. Environ. 2012, 121, 323-334. [CrossRef]

99. Verma, M.; Friedl, M.A.; Law, B.E.; Bonal, D.; Kiely, G.; Black, T.A.; Wohlfahrt, G.; Moors, E.J.; Montagnani, L.; Marcolla, B.; et al. Improving the performance of remote sensing models for capturing intra-and inter-annual variations in daily GPP: An analysis using global FLUXNET tower data. Agric. For. Meteorol. 2015, 214, 416-429. [CrossRef]

100. Wu, C.; Peng, D.; Soudani, K.; Siebicke, L.; Gough, C.M.; Altaf Arain, M.; Bohrer, G.; Lafleur, P.M.; Peichl, M.; Gonsamo, A.; et al. Land surface phenology derived from normalized difference vegetation index (NDVI) at global FLUXNET sites. Agric. For. Meteorol. 2017, 233, 171-182. [CrossRef]

101. Gonsamo, A.; Chen, J.M.; Price, D.T.; Kurz, W.A.; Wu, C. Land surface phenology from optical satellite measurements and $\mathrm{CO}_{2}$ eddy covariance technique. J. Geophys. Res. Biogeosci. 2012, 117. [CrossRef]

102. Zhang, Y.; Xiao, X.; Wu, X.; Zhou, S.; Zhang, G.; Qin, Y.; Dong, J. A global moderate resolution dataset of gross primary production of vegetation for 2000-2016. Sci. Data 2017, 4, 170165. [CrossRef]

103. Restrepo-Coupe, N.; Huete, A.; Davies, K.; Cleverly, J.; Beringer, J.; Eamus, D.; van Gorsel, E.; Hutley, L.B.; Meyer, W.S. MODIS vegetation products as proxies of photosynthetic potential along a gradient of meteorologically and biologically driven ecosystem productivity. Biogeosciences 2016, 13, 5587-5608. [CrossRef]

104. Jung, M.; Reichstein, M.; Margolis, H.A.; Cescatti, A.; Richardson, A.D.; Altaf Arain, M.; Arneth, A.; Bernhofer, C.; Bonal, D.; Chen, J.; et al. Global patterns of land-atmosphere fluxes of carbon dioxide, latent heat, and sensible heat derived from eddy covariance, satellite, and meteorological observations. J. Geophys. Res. Biogeosci. 2011, 116. [CrossRef] 
105. Balzarolo, M.; Vicca, S.; Nguy-Robertson, A.L.; Bonal, D.; Elbers, J.A.; Fu, Y.H.; Grünwald, T.; Horemans, J.A.; Papale, D.; Peñuelas, J.; et al. Matching the phenology of Net Ecosystem Exchange and vegetation indices estimated with MODIS and FLUXNET in-situ observation. Remote Sens. Environ. 2016, 174, 290-300. [CrossRef]

106. Richardson, A.D.; Hollinger, D.Y.; Dail, D.B.; Lee, J.T.; Munger, J.W.; O’keefe, J. Influence of spring phenology on seasonal and annual carbon balance in two contrasting New England forests. Tree Physiol. 2009, 29, 321-331. [CrossRef] [PubMed]

107. Nasahara, K.N.; Nagai, S. Development of an in situ observation network for terrestrial ecological remote sensing: The Phenological Eyes Network (PEN). Ecol. Res. 2015, 30, 211-223. [CrossRef]

108. Brown, J.F.; Howard, D.; Wylie, B.; Frieze, A.; Ji, L.; Gacke, C. Application-ready expedited MODIS data for operational land surface monitoring of vegetation condition. Remote Sens. 2015, 7, 16226-16240. [CrossRef]

109. Wingate, L.; Ogée, J.; Cremonese, E.; Filippa, G.; Mizunuma, T.; Migliavacca, M.; Moisy, C.; Wilkinson, M.; Moureaux, C.; Wohlfahrt, G.; et al. Interpreting canopy development and physiology using the EUROPhen camera network at flux sites. Biogeosciences 2015, 12, 7979-8034. [CrossRef]

110. Dai, J.; Wang, H.; Ge, Q. The spatial pattern of leaf phenology and its response to climate change in China. Int. J. Biometeorol. 2014, 58, 521-528. [CrossRef]

(C) 2020 by the authors. Licensee MDPI, Basel, Switzerland. This article is an open access article distributed under the terms and conditions of the Creative Commons Attribution (CC BY) license (http://creativecommons.org/licenses/by/4.0/). 